Hydrology and Earth System Sciences, 1, 000-000 (1997) (C) EGS

\title{
Modelling the ecosystem effects of nitrogen deposition: Model of Ecosystem Retention and Loss of Inorganic Nitrogen (MERLIN)
}

\author{
Bernard. J. Cosby ${ }^{1}$, Robert C. Ferrier ${ }^{2}$, Alan Jenkins ${ }^{3}$, Bridget A. Emmett ${ }^{4}$, Richard F. Wright ${ }^{5}$, \\ and Albert Tietema ${ }^{6}$ \\ ${ }^{1}$ Department of Environmental Sciences, University of Virginia, Charlottesville, VA, USA 22901 \\ 2 Macaulay Land Use Research Institute, Craigiebuckler, Aberdeen, AB9 2Q, UK \\ 3 Institute of Hydrology, Wallingford OXON OX10 8BB, UK \\ ${ }^{4}$ Institute of Terrestrial Ecology, Bangor Research Unit, Deiniol Road, Bangor, Gwynedd LL57 2UP, UK \\ 5 Norwegian Institute for Water Research, Box 173 Kjelsås, 0411 Oslo, Norway \\ ${ }^{6}$ Landscape and Environmental Research Group, University of Amsterdam, Nieuwe Prinsengracht 130, 1018 VZ Amsterdam, Netherlands
}

\section{Abstract}

A catchment-scale mass-balance model of linked carbon and nitrogen cycling in ecosystems has been developed for simulating leaching losses of inorganic nitrogen. The model (MERLIN) considers linked biotic and abiotic processes affecting the cycling and storage of nitrogen. The model is aggregated in space and time and contains compartments intended to be observable and/or interpretable at the plot or catchment scale. The structure of the model includes the inorganic soil, a plant compartment and two soil organic compartments. Fluxes in and out of the ecosystem and between compartments are regulated by atmospheric deposition, hydrological discharge, plant uptake, litter production, wood production, microbial immobilization, mineralization, nitrification, and denitrification. Nitrogen fluxes are controlled by carbon productivity, the C: $N$ ratios of organic compartments and inorganic nitrogen in soil solution. Inputs required are: 1) temporal sequences of carbon fluxes and pools; 2) time series of hydrological discharge through the soils, 3) historical and current external sources of inorganic nitrogen; 4) current amounts of nitrogen in the plant and soil organic compartments; 5) constants specifying the nitrogen uptake and immobilization characteristics of the plant and soil organic compartments; and 6) soil characteristics such as depth, porosity, bulk density, and anion/cation exchange constants. Outputs include: 1) concentrations and fluxes of $\mathrm{NO}_{3}$ and $\mathrm{NH}_{4}$ in soil solution and runoff; 2) total nitrogen contents of the organic and inorganic compartments; 3) C:N ratios of the aggregated plant and soil organic compartments; and 4) rates of nitrogen uptake and immobilization and nitrogen mineralization. The behaviour of the model is assessed for a combination of land-use change and nitrogen deposition scenarios in a series of speculative simulations. The results of the simulations are in broad agreement with observed and hypothesized behaviour of nitrogen dynamics in growing forests receiving nitrogen deposition.

\section{Introduction}

Forested ecosystems are commonly nitrogen deficient and retention of nitrogen within the ecosystems is usually essentially complete (e.g. Likens et al. 1977, Bormann $e t$ al. 1977, Vitousek and Howarth 1991, Johnson 1992). Although periodic or random disturbances can cause losses of inorganic nitrogen from forested ecosystems (e.g. Vitousek et al. 1979), these responses are generally transient, and nitrogen retention resumes when the disturbance is removed. Long-term inputs of inorganic nitrogen from atmospheric deposition may, however, produce 'nitrogen saturation' (e.g. Nilsson 1986, Ågren and Bosatta 1988, Aber et al. 1989, Brandon and Hüttl 1990, Stoddard 1994), a condition characterized by increased and persistent leaching losses of inorganic nitrogen from forests in streamflow or groundwater discharge (e.g. Aber et al. 1989, van Miegroet et al. 1992, van Miegroet and Johnson 1993). It is generally thought that the increased leaching associated with 'saturation' occurs when the combined inputs of inorganic nitrogen from internal sources (such as nitrogen mineralization and fixation) and external sources (such as atmospheric 
deposition and fertilization) exceed the nitrogen uptake requirements of plants and soil microorganisms (Stoddard 1994).

Nitrogen leaching can produce adverse effects on catchment resources. Inorganic nitrogen is usually lost from forests as nitrate, although in some cases ammonium is also leached. Nitrate is a strong acid anion and, if released to soils and surface waters, is effective as an acidifying agent and can mobilize toxic aluminium (Henriksen et al. 1988, Brown 1988). Assimilation of ammonium in soils or water can also have an acidifying effect. High concentrations of nitrate and ammonium in soils have been implicated in forest die-back in central Europe (van Breemen and van Dijk 1988). Nitrate and ammonium are also important nutrients for aquatic plants and decreased retention in catchment soils can result in elevated concentrations of these nutrients in surface waters which in turn can lead to eutrophication (National Academy of Sciences 1969). Leaching of nitrate to groundwater can lead to concerns for human health if the groundwater resource is exploited for water supply (National Research Council 1991).

There are indications that current levels of nitrogen deposition are resulting in increased mobilization of nitrogen in terrestrial and aquatic ecosystems (e.g. Emmett et al. 1993, Stoddard 1994, Dise and Wright 1995). Experimental manipulations of forested ecosystems have shown that inorganic nitrogen leaching can be induced or alleviated rather quickly with only modest changes in inorganic nitrogen inputs (Kahl et al. 1993, Wright and van Breemen 1995). Given that deposition of inorganic nitrogen has been projected to increase by at least $25 \%$ in the next 25 years in North America and Europe (Galloway et al. 1994), there is cause for concern that nitrogen leaching from forested ecosystems may increase.

There is a need, therefore, to develop an integrated scientific understanding of the many processes responsible for nitrogen retention and loss in forested ecosystems. In addition, the development of sound emissions control and resource management policies will require the ability to predict the onset and effects of nitrogen leaching. Mathematical models of nitrogen dynamics in terrestrial ecosystems are needed for both tasks. In particular, there is a need for a model that focuses on the retention and loss of inorganic nitrogen at the catchment scale, while maintaining sound process representations of biotic and abiotic interactions occurring within the catchment. In order to be most useful in the context of transboundary atmospheric pollution and deposition, the model should be applicable in regional as well as site specific analyses, and should rely on data readily obtainable at the catchment or landscape level.

The Model of Ecosystem Retention and Loss of Inorganic Nitrogen (MERLIN) was developed to meet these needs and this paper describes the conceptual basis, the mathematical structure and the implementation of MERLIN and describes a series of simulation exercises to demonstrate the potential use and range of response inherent in the model structure.

\section{Structure of the model}

\section{BACKGROUND}

Nitrogen dynamics within terrestrial ecosystems have been investigated by a variety of models focused primarily on nitrogen but formulated with different levels of complexity or for different applications. Dise and Wright (1995) constructed a simple empirical relationship describing catchment-scale nitrogen leaching from forest systems as a function of atmospheric deposition. Soil profile and field-scale models such as SOIL/SOILN have been developed for use on agricultural land cultivated for crops (Bergstrom and Jarvis 1991), and more recently have been applied to forest stands (Eckersten et al. 1995). Aber et al. (1991) constructed a lumped parameter model (VEGIE) linking organic matter turnover, nutrient dynamics, and forest productivity. More detailed process models linking nitrogen dynamics to carbon productivity have been constructed by Aber and Federer (1992; Pnet-CN), Running and Gower (1991; FOREST-BGC), and Thornley and Cannell (1992). Models linking nutrient cycling, nitrogen dynamics and the effects of atmospheric anthropogenic deposition on biogeochemical cycling have been formulated by $\mathrm{Li}$ et al. (1991; NuCM), and Groenenberg et al. (1995; NUCSAM). Catchment-scale models such as MAGICWAND (Ferrier et al. 1995, Jenkins et al. in press) have been used to examine the interactive effects of sulphur and nitrogen deposition on catchment soils and drainage waters. At the most detailed scale, complex nitrogen cycling models such as NICCCE (van Dam and van Breemen 1995) have been developed to interpret results of tracer experiments using a stable isotope of nitrogen $\left({ }^{15} \mathrm{~N}\right)$, as well as simulating the turnover of stable isotopes of carbon $\left({ }^{12} \mathrm{C}\right.$ and $\left.{ }^{13} \mathrm{C}\right)$.

Nitrogen dynamics are often included in models developed primarily for other purposes such as simulation of forest productivity, forest vitality or ecosystem succession. Productivity models have been developed to examine the consequences for forest growth of changes in environmental conditions such as meteorology or air quality, management actions such as thinning or treatment of disease, climate change and $\mathrm{CO}_{2}$ enhancement (Ågren et al. 1991, Landsberg et al. 1991). Although focused on carbon productivity, these models usually contain some level of detail about effects of nitrogen availability. Concern about the condition of forest health in Europe and North America has resulted in the development of ecophysiological models to assess forest vitality and nutritional imbalances especially in relation to nitrogen availability and magnesium deficiency, such as 
FIWALD (Schall 1991), and NAP (van Oene 1992), and exposure to pollutants such as ozone (Weinstein et al. 1991; TREGRO). Interest in the effects of climate change and nutrient availability on forest succession have been modelled in detail by Shugart (1984; FORET) and more recently Krauchi (1995; FORSUM). Eco-regional responses have been examined by Rastetter et al. (1991; GEM) in a generalized modelling approach examining the effects of increased global $\mathrm{CO}_{2}$ concentrations, temperature, and nitrogen inputs on carbon storage.

These existing models of nitrogen dynamics in terrestrial systems are in general focused on details of nitrogen cycling within the biotic community as a whole or within individual organisms. The mobility of nitrogen in the abiotic environment is usually not considered in detail. Agricultural runoff models are a notable exception, but these are limited in application and not intended for forested ecosystems. Yet it is the mobility of nitrogen in the abiotic environment that is of primary concern for acidification of soils and acidification and eutrophication of surface waters.

\section{CONCEPTUAL BASIS OF THE MODEL}

MERLIN is a model of linked biotic and abiotic processes affecting the cycling and storage of nitrogen in an ecosystem (Fig. 1). The conceptual representation of the ecosystem is highly aggregated in space and time. The compartments and processes included in the model are intended to be observable and/or interpretable at the plot or catchment scale (rather than at the scale of individual organisms or soil pedons). The time steps are monthly to yearly and the intended periods of simulation are decadal (50 to 100 years or more). The processes and fluxes in the model can be grouped roughly as transformations and transport of inorganic nitrogen species (unshaded left side of Fig. 1); and translocation, transport and storage of organic nitrogen (shaded right side of Fig. 1). The organic processes are further subdivided into those mediated by plants and those mediated by soil microorganisms. The fluxes of nitrogen (open arrows in Fig. 1) through the abiotic and biotic pathways are controlled or affected by hydrological processes, the physical characteristics of the soil matrix and the fluxes of organic carbon (closed arrows in Fig. 1) through the biotic compartments.

\section{Model structure}

Two species of inorganic nitrogen $\left(\mathrm{NO}_{3}\right.$ and $\left.\mathrm{NH}_{4}\right)$ are considered in the model. Both have a dissolved phase in soil solution and the model provides the potential for both to have an adsorbed phase (cation and anion exchange) on the soil matrix. Both forms of inorganic nitrogen can be incorporated into organic matter. The incorporation of inorganic nitrogen into the organic compartments is regulated by aggregated plant and soil microbial processes and by availability of inorganic nitrogen in the abiotic environment (Fig. 1). The conceptualization is that uptake and immobilization are: 1) directly proportional to concentrations of inorganic nitrogen in soil solution (i.e., substrate limited at some level); 2) directly proportional to carbon fluxes through each organic compartment (i.e., a function of carbon produc-

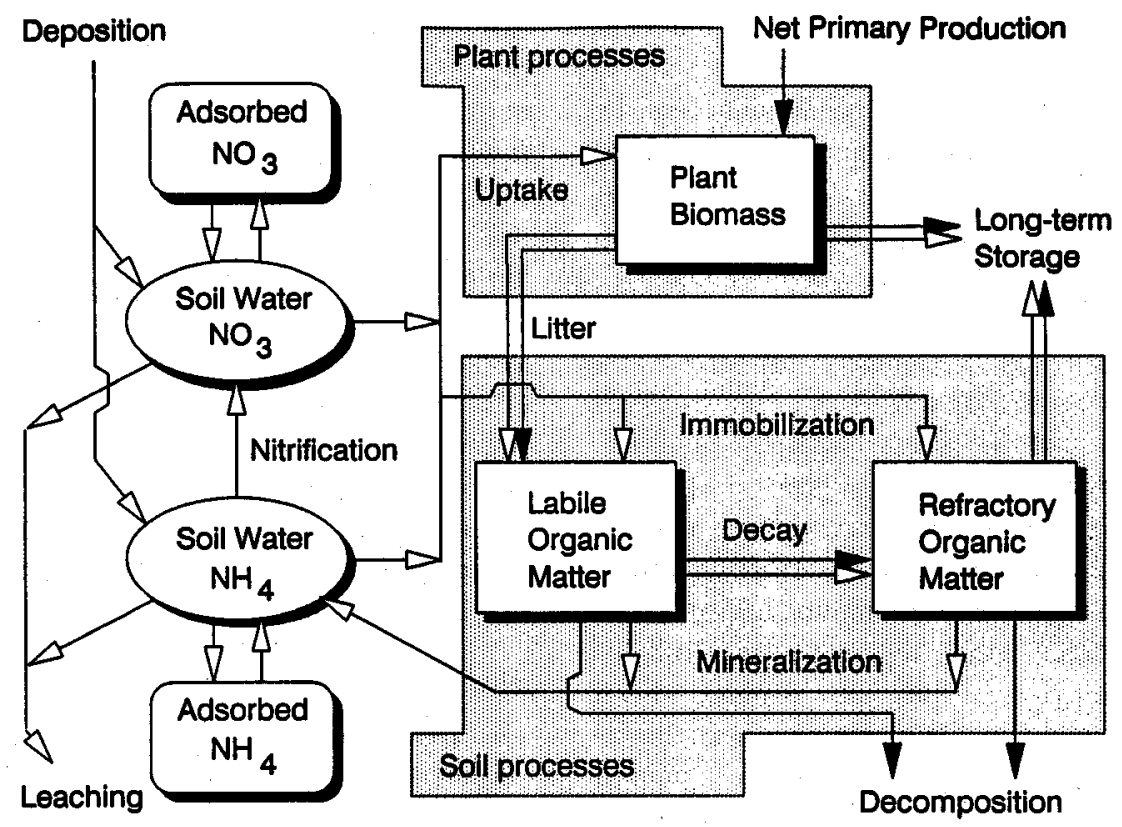

Fig. 1 A diagram of the conceptual basis of the MERLIN model. 
tivity); and 3) inversely proportional to the nitrogen status of each organic compartment (i.e., negative feedback for regulation to a 'preferred' nitrogen content). Each of the rectangular boxes in Fig. 1 represents a pool of organic material containing both carbon and nitrogen. The fluxes of nitrogen through these organic compartments are linked to the fluxes of carbon, which are specified as inputs to the model.

The plant compartment is an aggregated pool of carbon and nitrogen representing the 'active' portion of the ecosystem. This pool conceptually includes, for example, foliage and fine roots for forests and perhaps whole plants for grasslands. Long-term storage losses from this'pool (Fig. 1) can be thought of as wood production in forests, or production of any plant structure that removes carbon and nitrogen from the ecosystem for the duration of the simulation. The litter flux represents the sum of all organic material transferred to the soil compartments and includes leaf litter, fine-root death, and woody debris. Carbon mass balance for this compartment requires that the difference between inputs and outputs equals the rate of change of the compartment. Thus, specified time sequences of plant biomass, litter production and long-term storage determine the net primary productivity of the system for that period of simulation (Fig. 1). For forested systems, time sequences of standing crop, litter production and wood production are well (or at least approximately) known, and obtaining these input sequences for a model application is relatively straightforward.

Soil organic material (Fig. 1) is divided into labile organic matter (LOM) and refractory organic matter (ROM). Each compartment is a highly aggregated pool of carbon and nitrogen representing accumulated non-living organic compounds in the ecosystem. These materials provide the energy substrate for growth of soil microorganisms, and this microbial activity results in the carbon and nitrogen fluxes of interest in ecosystem soils (Fig. 1). In fact, these pools contain live microorganisms, and thus the compartments are not strictly 'non-living'. However, field measurements are typically not capable of distinguishing living microbial biomass from detrital material, so the distinction is not maintained in the model. The LOM pool may be most readily identified with the forest floor in forested systems. Alternately, it may represent an accumulation of a number of years (cohorts) of litter. The soil $\mathrm{A}$ and $\mathrm{O}$ horizons may also comprise part of the LOM compartment. The LOM is intended to provide a soil organic matter compartment that can respond rather quickly to changing external conditions and inputs. The ROM pool, on the other hand, represents the bulk of carbon and nitrogen present in soil profiles down through the $B$ and $C$ horizons. It might also include the accumulation of humic materials higher in the soil profile. In general, the interpretation of each aggregated compartment will vary with application depending on the quality and quantity of data available from the site.
Labile organic matter is conceived of as relatively 'fresh' material, and thus the litter flux from the plant compartment enters this pool. Carbon leaves this pool by two pathways: decomposition and decay. Decomposition is defined as transformation of organic carbon to inorganic carbon $\left(\mathrm{CO}_{2}\right)$. Decay is defined as degradation of the quality of the organic matter (i.e., transformation from labile to refractory material). Carbon mass balance for the LOM compartment requires that the difference between inputs and outputs equals the rate of change of the compartment. For instance, specifying time sequences of LOM standing crop, litter production and decomposition (Fig. 1) determines the time series of decay for the compartment. Litter production is determined by the carbon balance for the plant biomass compartment so the additional carbon inputs required for LOM dynamics in a model application are time sequences of LOM standing crop and decomposition.

Refractory organic matter is conceived of as the bulk of slowly decomposing organic material in the soil. Carbon enters this pool by the decay pathway. Decomposition of this material is conceived of as occurring more slowly than in the LOM compartment, but the larger amount of material in the compartment may result in a mineralization flux as large or larger than that from the LOM compartment. Long-term storage losses from the ROM represent losses of organic matter to peat formation or losses through leaching of dissolved organic compounds in drainage waters. This flux might well be ignored for many upland forested systems and grasslands. Carbon mass balance for the ROM compartment requires that the difference between inputs and outputs equals the rate of change of the compartment. For this compartment, specifying time sequences of ROM standing crop and long-term storage losses would determine the time sequence of decomposition because the sequence of decay is determined by the carbon mass balance on the LOM compartment (Fig. 1).

Three characteristics of MERLIN can be identified that distinguish this conceptual approach from other models of nitrogen cycling in ecosystems: 1) the emphasis on the coupling and interaction of hydrological and abiotic processes affecting nitrogen with the biotic cycling of nitrogen within the ecosystem; 2) the focus on aggregated carbon dynamics as forcing functions for biotic transformations of nitrogen; and 3) , the identification of organic compartments and fluxes in the model with readily observable or measurable characteristics of ecosystems.

\section{Model application.}

To apply MERLIN, a number of inputs must be specified for the model. Firstly, the sequences of carbon fluxes and pools described above must be provided (i.e., time series of: plant standing crop; litter and wood production; forest floor standing crop and decomposition; 
and the amount of organic matter in the bulk soil and its decomposition). The intention is that some reasonable values for these carbon sequences can be derived for a given site simply by observing the landscape at the site. Knowledge that the current ecosystem contains a 60 year old temperate, mixed hardwood forest on an inceptisol in Virginia or a 30 year old plantation of Sitka spruce on a spodosol in Wales should provide a good deal of information about the required carbon pools and fluxes (and their recent history) even in the absence of measurements at the site in question. Secondly, the current nitrogen status of the ecosystem is needed. This will require measurements of the current nitrogen content of the important biotic and abiotic pools at the site. Thirdly, information is needed about the soil and hydrological properties at the site. Finally, the history of nitrogen inputs (primarily from the atmosphere, but also any history of nitrogen manipulation such as fertilization, etc.) must be specified.

The procedure is then to run the model (with the assumed historical carbon sequences and nitrogen inputs driving the simulation) for several decades of the recent past, arriving at the present day with the 'correct' nitrogen content of each organic compartment and the 'correct' leaching losses of the catchment or plot. 'Correct' in this case means that the simulated $\mathrm{C}: \mathrm{N}$ ratios of the organic compartments match those measured for the system and the simulated leaching losses also match the observed. If a 'correct' match is not obtained, the parameters of the model are adjusted and the hindcast run again. If this iterative procedure converges to a 'correct' match, then the model is considered calibrated for the site. The emphasis on running a hindcast as part of the calibration procedure (rather than just using current observed nitrogen status as initial conditions for the model and running forward from the present) stems from the belief that the future behaviour of a system depends not only on its present status but is also strongly conditioned by the pathway followed to reach the present status. The calibration procedure described above utilizes historical assumptions to constrain the future behaviour of the model. While the historical assumptions are just that (assumed, not known), it is often the case that a 'reasonable' estimate of the recent past of an ecosystem can be made. Constraining a model to reproduce this 'reasonable' past as well as to match current observed conditions should result in the simulation of more 'reasonable' and reliable future behaviours of the system.

\section{MATHEMATICAL FORMULATION OF THE MODEL}

MERLIN is a dynamic model intended for simulation of temporal changes in nitrogen state variables in response to temporal changes of input forcing functions. Nitrogen state variables in the model include inorganic nitrogen species $\left(\mathrm{NO}_{3}\right.$ and $\left.\mathrm{NH}_{4}\right)$ and organic nitrogen pools (in the plant and soil compartments). Input forcing functions include: a) time series of atmospheric deposition of inorganic nitrogen (and simulated additions or removals of inorganic nitrogen); b) the temporal pattern of water discharge through the catchment; and c) time series of fluxes and/or pool sizes of organic carbon in the plant and soil compartments. Changes in the nitrogen state variables are regulated by linear and non-linear processes that are themselves functions of the instantaneous values of the nitrogen state variables and the input forcing functions. The inputs, outputs, state variables, equations and parameters are defined and summarized in Tables 1 and 2.

Inorganic nitrogen exists in soil solution and surface waters as $\mathrm{NO}_{3}$ or $\mathrm{NH}_{4}$ or both. In the discussion and equations that follow, the generalized notation $\mathrm{Nx}$ is used to represent either $\mathrm{NO}_{3}$ or $\mathrm{NH}_{4}$ whenever both species participate in a process. Generalized equations and parameters are used in the text. The specific equations and parameters for each nitrogen species are given in Tables 1 and 2.

\section{Catchment input and output fluxes.}

Nitrogen inputs to the model ecosystem are time series of inorganic nitrogen fluxes added to the soil solution. The primary inputs are atmospheric deposition of $\mathrm{NO}_{3}$ and $\mathrm{NH}_{4}$ Deposition is considered to be a combined function of wet (precipitation) and dry (gaseous and particulate) nitrogen inputs:

$$
\mathrm{FNx}_{\mathrm{dep}}=\mathrm{Q}_{\mathrm{ppt}} \times(\mathrm{Nx})_{\mathrm{ppt}} \times \mathrm{DDF}_{\mathrm{Nx}}
$$

where $\mathrm{FNx}_{\mathrm{dep}}$ is the deposition flux of the inorganic nitrogen species $\left(\mathrm{mmol} \mathrm{m}^{-2} \mathrm{yr}^{-1}\right), \mathrm{Q}_{\mathrm{ppt}}$ is the precipitation flux $\left(\mathrm{m} \mathrm{yr}^{-1}\right),(\mathrm{Nx})_{\mathrm{ppt}}$ is the concentration of the inorganic nitrogen species in precipitation $\left(\mathrm{mmol} \mathrm{m}^{-3}\right)$, and $\mathrm{DDF}_{\mathrm{Nx}}$ is the dry deposition factor for the inorganic nitrogen species, a unitless scale factor for expressing total deposition as a function of wet deposition. Separate deposition equations are used for $\mathrm{NO}_{3}$ and $\mathrm{NH}_{4}$ in the model (Table 1). Provision is also made in the model for simulation of additional sources of inorganic nitrogen (e.g. fertilization, biological fixation, etc.). Time series of all inorganic nitrogen inputs must be specified a priori as forcing functions for the model.

Nitrogen leaching losses from the model ecosystem occur as inorganic nitrogen in soil solution runoff. Losses of inorganic nitrogen by this mechanism are the primary outputs of the model. Leaching fluxes are functions of soil solution concentrations of inorganic nitrogen species and vary during the simulation as these concentrations vary in response to the biotic and abiotic processes: A central objective in developing MERLIN, therefore, was to design explicitly a catchment-scale mass-balance model with the primary function of simulating runoff concentrations of inorganic nitrogen species. 
Table 1. Equations in the model.

\section{Organic compartments}

$$
\begin{aligned}
& \frac{d}{d t} \mathrm{C}_{\mathrm{plt}}=\mathrm{FC}_{\mathrm{npp}}-\mathrm{FC}_{\mathrm{lit}}-\mathrm{FC}_{\mathrm{wd}}
\end{aligned}
$$

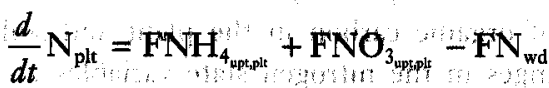

$$
\begin{aligned}
& \frac{d}{d t} \mathrm{C}_{\mathrm{LOM}}=\mathrm{FC}_{\mathrm{li}}-\mathrm{FC}_{\mathrm{dcmp} \mathrm{L} / \mathrm{M}}-\mathrm{FC}_{\mathrm{dcy}}
\end{aligned}
$$

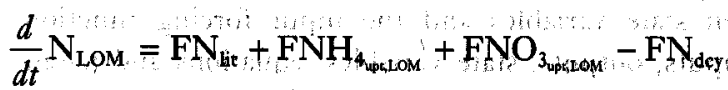

$$
\begin{aligned}
& \frac{d}{d t} \mathrm{C}_{\mathrm{ROM}}-\mathrm{FC}_{\mathrm{dcy}}-\mathrm{FC}_{\mathrm{dcmp}, \mathrm{ROM}}-\mathrm{FC}_{\mathrm{exp}}
\end{aligned}
$$

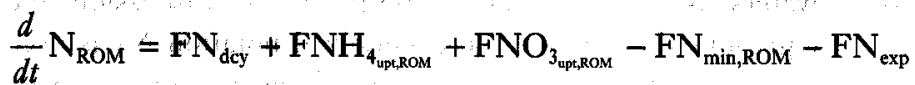

\section{Inorganic nitrogen}

$$
\begin{aligned}
& \frac{d}{d t}\left(\mathrm{NH}_{4}\right)_{\text {soil }}=-\frac{\mathrm{SMS}}{\mathrm{SPV}} \times \frac{d}{d t} \mathrm{E}_{\mathrm{NH}_{4}}
\end{aligned}
$$

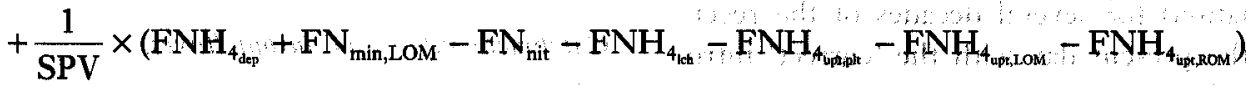

$$
\begin{aligned}
& \frac{d}{d t}\left(\mathrm{NO}_{3}\right)_{\text {soil }}=-\frac{\mathrm{SMS}}{\mathrm{SPV}} \times \frac{d}{d t} \mathrm{E}_{\mathrm{NO}_{3}}
\end{aligned}
$$

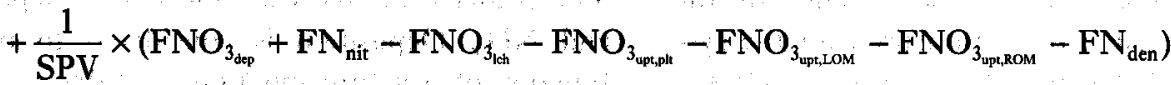

\section{Catchment inputs and outputs}

\section{Deposition of ammonium}

$\mathrm{FNH}_{4 \text { dep }}=\mathrm{Q}_{\mathrm{ppt}} \times\left(\mathrm{NH}_{4}\right)_{\mathrm{ppt}} \times \mathrm{DDF}_{\mathrm{NH}_{4}}$

\section{Deposition of nitrate}

$\mathrm{FNO}_{3 \mathrm{dep}}=\mathrm{Qppt}_{\mathrm{pp}} \times\left(\mathrm{NO}_{3}\right)_{\mathrm{ppt}} \times \mathrm{DDF}_{\mathrm{NO}_{3}}$
Leaching of ammonium

$\mathrm{FNH}_{4 \text { loh }}=\mathrm{Q}_{\text {lch }} \times\left(\mathrm{NH}_{4}\right)_{\text {soil }}$

\section{Leaching of nitrate}

$$
\mathrm{FNO}_{3_{\text {lch }}}=\mathrm{Q}_{\mathrm{lch}} \times\left(\mathrm{NO}_{3}\right)_{\text {soil }}
$$

Adsorption of ammonium by soil matrix

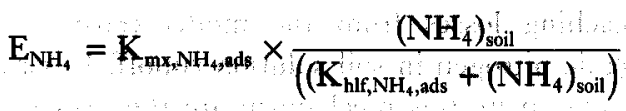

Nitrification

$\mathrm{FN}_{\text {nit }}=\mathrm{NIT} \times\left(\mathrm{NH}_{4}\right)_{\text {soil }} \times \mathrm{SPV}$
Adsorption of nitrate, by soil matrix

$$
\mathrm{E}_{\mathrm{NO}_{3}}=\mathrm{K}_{\mathrm{mx}, \mathrm{NQ} \mathrm{O}_{3}, \mathrm{ads}} \times \frac{\left(\mathrm{NO}_{3}\right)_{\text {soil }}}{\left(\left(\mathrm{K}_{\mathrm{hlf}, \mathrm{NO}, \mathrm{ads}}+\left(\mathrm{NO}_{3}\right)_{\text {soil }}\right)\right.}
$$


Ammonium uptake by plants

$$
\begin{aligned}
& \mathrm{FNH}_{4}=\mathrm{K}_{\mathrm{mx}, \mathrm{NH}_{4}, \mathrm{plt} \text { plt }} \times \frac{\left(\mathrm{NH}_{4}\right)_{\text {soil }}}{\left(\mathrm{K}_{\mathrm{hl}, \mathrm{NH}_{4}, \mathrm{plt}}+\left(\mathrm{NH}_{4}\right)_{\text {soil }}\right)} \\
& \mathrm{K}_{\mathrm{mx}, \mathrm{NH}_{4}, \mathrm{plt}}=\mathrm{FC}_{\mathrm{ppp}} \times \mathrm{M}_{\mathrm{NH}_{4}, \mathrm{plt}} \\
& \mathrm{K}_{\mathrm{hlf}, \mathrm{NH}_{4}, \mathrm{plt}}=\mathrm{K}_{\mathbf{b}} \times \exp \left(\frac{\mathrm{C}: \mathrm{N}_{0, \mathrm{plt}}-\mathrm{C}: \mathrm{N}_{\mathrm{plt}}}{\mathrm{S}_{\mathrm{NH}_{4}, \mathrm{plt}}}\right)
\end{aligned}
$$

Ammonium immobilization by LOM

$$
\begin{aligned}
& \mathrm{FNH}_{4 \text { uq, LOM }}=\mathrm{K}_{\mathrm{mx}, \mathrm{NH}_{4}, \mathrm{LOM}} \times \frac{\left(\mathrm{NH}_{4}\right)_{\text {soil }}}{\left(\mathrm{K}_{\mathrm{hl}, \mathrm{NH}_{4}, \mathrm{LOM}}+\left(\mathrm{NH}_{4}\right)_{\text {soil }}\right)} \\
& \mathrm{K}_{\mathrm{mx}, \mathrm{NH}_{4, \mathrm{LOM}}}=\mathrm{FC}_{\mathrm{domp}, \mathrm{LOM}} \times \mathrm{M}_{\mathrm{NH}_{4}, \mathrm{LOM}} \\
& \mathrm{K}_{\mathrm{hif,NH}, \mathrm{LOM}}=\mathrm{K}_{0} \times \exp \left(\frac{\mathrm{C}: \mathrm{N}_{0, \mathrm{LOM}}-\mathrm{C}: \mathrm{N}_{\mathrm{LOM}}}{\mathrm{S}_{\mathrm{NH}_{4}, \mathrm{LOM}}}\right)
\end{aligned}
$$

\section{Ammonium immobilization by ROM}

$$
\begin{aligned}
& \mathrm{FNH}_{4}{ }_{\text {vpr, RoM }}=\mathrm{K}_{\mathrm{mx}, \mathrm{NH}_{4}, \mathrm{ROM}} \times \frac{\left(\mathrm{NH}_{4}\right)_{\text {soil }}}{\left(\mathrm{K}_{\mathrm{hlf}, \mathrm{NH}_{4}, \mathrm{ROM}}+\left(\mathrm{NH}_{4}\right)_{\text {soil }}\right)} \\
& \mathrm{K}_{\mathrm{mx}, \mathrm{NH}_{4}, \mathrm{ROM}}=\mathrm{FC}_{\mathrm{dcmp}, \mathrm{ROM}} \times \mathrm{M}_{\mathrm{NH}_{4}, \mathrm{ROM}} \\
& \mathrm{K}_{\mathrm{hlf,NH}, \mathrm{ROM}}=\mathrm{K}_{0} \times \exp \left(\frac{\mathrm{C}: \mathrm{N}_{0, \mathrm{ROM}}-\mathrm{C}: \mathrm{N}_{\mathrm{ROM}}}{\mathrm{S}_{\mathrm{NH}_{4}, \mathrm{ROM}}}\right)
\end{aligned}
$$

Nitrate uptake by plants

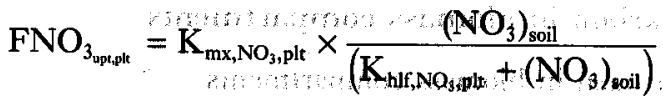

$$
\begin{aligned}
& \mathrm{K}_{\mathrm{mx}, \mathrm{NO}_{3}, \mathrm{plt}}=\mathrm{FC}_{\mathrm{mpp}} \times \mathrm{M}_{\mathrm{NO}_{3}, \mathrm{plt} .} \\
& \mathrm{K}_{\mathrm{hl}, \mathrm{NO}_{3}, \mathrm{plt}}=\mathrm{K}_{6} \times \exp \left(\frac{\mathrm{C}: \mathrm{N}_{0, \mathrm{plt}}-\mathrm{C}: \mathrm{N}_{\mathrm{plt}}}{\mathrm{S}_{\mathrm{NO}_{3, \mathrm{plt}}}}\right)
\end{aligned}
$$

Nitrate immobilization by LQM

$$
\begin{aligned}
& \mathrm{FNO}_{3_{\mathrm{up}, \mathrm{LOM}}}=\mathrm{K}_{\mathrm{mx}, \mathrm{NO}, \mathrm{LOM}} \times \frac{\left(\mathrm{NO}_{3}\right)_{\text {soil }}}{\left(\mathrm{K}_{\mathrm{hlf}, \mathrm{NO}_{3}, \mathrm{LOM}}+\left(\mathrm{NO}_{3}\right)_{\mathrm{soil}}\right)} \\
& \mathrm{K}_{\mathrm{mx}, \mathrm{NO}_{3}, \mathrm{LOM}}=\mathrm{FC}_{\mathrm{dcmp}, \mathrm{LOM}} \times \mathrm{M}_{\mathrm{NO}_{3}, \mathrm{LOM}} \\
& \mathrm{K}_{\mathrm{hlf}, \mathrm{NO}_{3} \mathrm{LOM}}=\mathrm{K}_{0} \times \exp \left(\frac{\mathrm{C}: \mathrm{N}_{0, \mathrm{LOM}}-\mathrm{C}: \mathrm{N}_{\mathrm{LOM}}}{\mathrm{S}_{\mathrm{NO}_{3} \mathrm{LOM}}}\right)
\end{aligned}
$$

Nitrate immobilization by ROM

$$
\begin{aligned}
& \mathrm{FNO}_{3_{\mathrm{up}, \mathrm{ROM}}}=\mathrm{K}_{\mathrm{mx}, \mathrm{NO}}, \mathrm{ROM} \\
& \mathrm{K}_{\mathrm{mx}, \mathrm{NO}_{3}, \mathrm{ROM}}=\mathrm{FC}_{\mathrm{dcmp}, \mathrm{LOM}} \times \mathrm{M}_{\mathrm{NO}_{3}, \mathrm{ROM}} \\
& \mathrm{K}_{\mathrm{hlf}, \mathrm{NO}_{3}, \mathrm{ROM}}=\mathrm{K}_{\mathbf{0}} \times \exp \left(\frac{\left.\mathrm{C}: \mathrm{NO}_{3, \mathrm{ROM}}\right)_{\mathrm{soil}}-\mathrm{C}: \mathrm{N}_{\mathrm{ROM}}}{\mathrm{S}_{\mathrm{NO}_{3}, \mathrm{ROM}}}\right)
\end{aligned}
$$

Mineralization of LOM

$\mathrm{FN}_{\text {min,LOM }}=\frac{\mathrm{FC}_{\mathrm{dcmp}, \mathrm{LOM}}}{\mathrm{C}: \mathrm{N}_{\mathrm{LOM}}}$

\section{Nitroget transfer to wood}

$\mathrm{FN}_{\mathrm{wd}}=\frac{\mathrm{FC}_{\mathrm{wdd}}}{\mathrm{C}: \mathrm{N}_{\mathrm{wd}}}$

Nitrogen transfer from LOM to ROM

$$
\mathrm{FN}_{\mathrm{dcy}}=\frac{\mathrm{FC}_{\mathrm{dcy}}}{\mathrm{C}: \mathrm{N}_{\mathrm{LOM}}}
$$

\section{Mineralization of ROM}

$\mathrm{FN}_{\text {min,ROM }}=\frac{\mathrm{FC}_{\mathrm{dcmp}, \mathrm{ROM}}}{\mathrm{C}: \mathrm{N}_{\mathrm{ROM}}}$

\section{Nitrogen transfer in litter}

$\mathrm{FN}_{\mathrm{lit}}=\frac{\mathrm{FC}_{\mathrm{lit.}}}{\mathrm{C}: \mathrm{N}_{\mathrm{plt}}}$

\section{Organic nitrogen export}

$\mathrm{FN}_{\exp }=\frac{\mathrm{FC}_{\mathrm{exp}}}{\mathrm{C}: \mathrm{N}_{\mathrm{ROM}}}$ 
Table 2. Variables and parameters in the model. Items in bold are inputs required by themodel

Description

Carbon and Nitrogen Pools

Organic carbon in biomass compartments

Organic nitrogen in biomass compartments

Carbon-to-nitrogen ratio of biomass compartments

Exchangeable $\mathrm{NH}_{4}$ and $\mathrm{NO}_{3}$ on soil matrix

Concentrations of $\mathrm{NH}_{4}$ and $\mathrm{NO}_{3}$ in soil solution

International Carbon and Nitrogen Fluxes

Wood Production

Litter Production

Decomposition of LOM and ROM

Organic carbon export

Denitrification

Net primary production of plants

Decay (transfer from LOM to ROM)

Biomass transfers of organic nitrogen

Nitrification

Mineralization of LOM and ROM

Uptake of $\mathrm{NH}_{4}$ and $\mathrm{NO}_{3}$ by plants, LOM and ROM
Variable and Parameter Names

$$
\begin{aligned}
& C_{\text {plt }} C_{L O M} C_{R O M} \\
& \mathrm{~N}_{\text {plt }} \mathrm{N}_{\text {LOM }} \mathrm{N}_{\mathrm{ROM}} \\
& \text { C: } \mathrm{N}_{\text {plt }} \text { C:N } \mathrm{N}_{\mathrm{LOM}} \mathrm{C}: \mathrm{N}_{\mathrm{ROM}} \\
& \mathrm{E}_{\mathrm{NH}_{4}} \mathrm{E}_{\mathrm{NO}_{3}} \\
& \left(\mathrm{NH}_{4}\right)_{\text {soil }}\left(\mathrm{NO}_{3}\right)_{\text {soil }}
\end{aligned}
$$

Units

$\operatorname{mmol~C~m}{ }^{-2}$

$\mathrm{mmol} \mathrm{N} \mathrm{m}^{-2}$

mol C per mol $\mathrm{N}$

$\mathrm{mmol} \mathrm{N} \mathrm{kg}{ }^{-1}$

$\mathrm{mmol} \mathrm{N} \mathrm{m}{ }^{-3}$

\section{Deposition and Discharge Parameters and Fluxes}

Precipitation amount, soil discharge

$\mathrm{m} \mathrm{yr}^{-1}$

$\operatorname{mmol~} \mathrm{N} \mathrm{m}^{-3}$

unitless

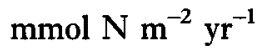

$\mathrm{mmol} \mathrm{N} \mathrm{m}^{-2} \mathrm{yr}^{-1}$

mol C per mol $\mathbf{N}$ mol $\mathrm{N}$ per mol C mol $\mathrm{N}$ per mol $\mathrm{C}$ unitless

$\mathrm{K}_{\mathbf{0}} \quad \mathrm{mmol} \mathrm{m}^{-3}$

$\mathbf{O}_{\mathrm{ppt}} \mathbf{Q}_{\mathrm{lch}}$

$\left(\mathrm{NH}_{4}\right)_{\mathrm{ppt}}\left(\mathrm{NO}_{3}\right)_{\mathrm{ppt}}$

$\mathrm{DDF}_{\mathrm{NH}_{4}} \mathrm{DDF}_{\mathrm{NO}_{3}}$

$\mathrm{FNH}_{4 \text { dep }} \mathrm{FNO}_{3_{\text {dep }}}$

$\mathrm{FNH}_{4_{\text {lch }}}$ FNO $_{3_{\text {lch }}}$

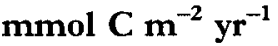
$\mathrm{mmol} \mathrm{C} \mathrm{m} \mathrm{m}^{-2} \mathrm{yr}^{-1}$

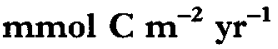
$\mathrm{mmol} \mathrm{C} \mathrm{m}{ }^{-2} \mathrm{yr}^{-1}$ $\mathrm{mmol} \mathrm{N} \mathrm{m}^{-2} \mathrm{yr}^{-1}$ $\mathrm{mmol} \mathrm{C} \mathrm{m} \mathrm{mr}^{-2}$ $\mathrm{mmol} \mathrm{C} \mathrm{m}^{-2} \mathrm{yr}^{-1}$ $\mathrm{mmol} \mathrm{N} \mathrm{m}{ }^{-2} \mathrm{yr}^{-1}$ $\mathrm{mmol} \mathrm{N} \mathrm{m}{ }^{-2} \mathrm{yr}^{-1}$ $\mathrm{mmol} \mathrm{N} \mathrm{m}{ }^{-2} \mathrm{yr}^{-1}$ $\mathrm{FNH}_{4}$ upt,plt ${ }_{\mathrm{p}} \mathrm{FNH}_{4} \mathrm{upt,LOM} \mathrm{FNH}_{4} \mathrm{upt,ROM} \mathrm{mmol} \mathrm{N}^{-2} \mathrm{yr}^{-1}$

$$
\text { (1) }
$$

Maximum $\mathrm{NH}_{4}$ or $\mathrm{NO}_{3}$ uptake per unit of

Steepness of decline in uptake half-saturation parameter as C:N's of biomass increase

$\mathrm{M}_{\mathrm{NO}_{3}, \text { plt }} \mathrm{M}_{\mathrm{NO}_{3}, \mathrm{LOM}} \mathbf{M}_{\mathrm{NO}_{3}, \mathrm{ROM}}$

$\mathbf{S}_{\mathrm{NH}_{4}, \mathrm{plt}} \mathbf{S}_{\mathrm{NH}_{4}, \mathrm{LOM}} \mathbf{S}_{\mathrm{NH}_{4}, \mathrm{ROM}}$

$\mathrm{S}_{\mathrm{NO}_{3}, \mathrm{plt}} \mathrm{S}_{\mathrm{NO}_{3}, \mathrm{LOM}} \mathrm{S}_{\mathrm{NO}_{3}, \mathrm{ROM}}$ 
Table 2. Continued

\begin{tabular}{|c|c|c|}
\hline Description & Variable and Parameter Names & Units \\
\hline Maximum rate uptake of $\mathrm{NH}_{4}$ and $\mathrm{NO}_{3}$ & $\begin{array}{l}\mathrm{K}_{\mathrm{mx}, \mathrm{NH}_{4}, \mathrm{plt}} \mathrm{K}_{\mathrm{mx}, \mathrm{NH}_{4}, \mathrm{LOM}} \mathrm{K}_{\mathrm{mx}, \mathrm{NH}_{4}, \mathrm{ROM}} \\
\mathrm{K}_{\mathrm{mx}, \mathrm{NO}_{3}, \mathrm{plt}} \mathrm{K}_{\mathrm{mx}, \mathrm{NO}_{3}, \mathrm{LOM} \mathrm{K}_{\mathrm{mx}, \mathrm{NO}_{3}, \mathrm{ROM}}}\end{array}$ & $\mathrm{mmol} \mathrm{N} \mathrm{m}^{-3} \mathrm{yr}^{-}$ \\
\hline Half-saturation parameter, uptake of $\mathrm{NH}_{4}$ and $\mathrm{NO}_{3}$ & $\begin{array}{l}\mathrm{K}_{\mathrm{hlf,NH}}, \mathrm{plt} \\
\mathrm{K}_{\mathrm{hlf,NH}}, \mathrm{LOM} \mathrm{K}_{\mathrm{hlf,NH}}, \mathrm{ROM} \\
\mathrm{K}_{\mathrm{hlf}, \mathrm{NO}_{3} \text {,plt }} \mathrm{K}_{\mathrm{hlf}, \mathrm{NO}_{3}, \mathrm{LOM}} \mathrm{K}_{\mathrm{hlf,NO}}, \mathrm{ROM}\end{array}$ & $\mathrm{mmol} \mathrm{N} \mathrm{N}^{-3}$ \\
\hline \multicolumn{3}{|l|}{ Soil Parameters } \\
\hline Depth & SDP & $\mathbf{m}$ \\
\hline Porosity & SDP & unitless \\
\hline Bulk Density & SBD & $\mathrm{kg} \mathrm{m}^{-3}$ \\
\hline Maximum adsorption capacity of $\mathrm{NH}_{4}$ and $\mathrm{NO}_{3}$ & $\mathbf{K}_{\mathrm{mx}, \mathrm{NH}_{4}, \mathrm{ads}} \mathbf{K}_{\mathrm{mx}, \mathrm{NO}_{3}, \mathrm{ads}}$ & $\mathrm{mmol} \mathrm{N} \mathrm{kg}^{-1}$ \\
\hline $\begin{array}{l}\text { Half saturation constant, } \mathrm{NH}_{4} \text { and } \mathrm{NO}_{3} \\
\text { adsorption }\end{array}$ & 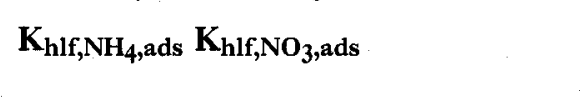 & $\mathbf{m m o l ~} \mathrm{N} \mathrm{m}^{-3}$ \\
\hline Nitrification rate constant & NIT & $\mathrm{yr}^{-1}$ \\
\hline Pore volume per unit area & SPV & $\mathrm{m}$ \\
\hline Mass per unit area & SMS & $\mathrm{kg} \mathrm{m}^{-2}$ \\
\hline
\end{tabular}

\section{Biomass Transfer Parameters}

C:N ratio of wood produced from plants

C: $\mathbf{N}_{\mathbf{w d}}$

mol C per mol $\mathbf{N}$

C:N ratio of organic matter export from ROM

C: $\mathrm{N}_{\exp }$

mol C per mol $\mathbf{N}$

C:N ratio or organic matter decomposed by

LOM and ROM (optional)

C: $\mathrm{N}_{\text {demp,LOM }}$ C: $\mathrm{N}_{\text {demp,ROM }}$

mol C per mol N

C:N ratio of organic matter transferred from

C: $\mathrm{N}_{\mathrm{dcy}}$

mol C per mol N

$$
\mathrm{FNx}_{1 \mathrm{lch}}=\mathrm{Q}_{\mathrm{lch}} \times(\mathrm{Nx})_{\text {soil }}
$$

where $\mathrm{FNx}_{\mathrm{lch}}$ is the leaching flux of the inorganic nitrogen species $\left(\mathrm{mmol} \mathrm{m} \mathrm{m}^{-2} \mathrm{yr}^{-1}\right), \mathrm{Q}_{\mathrm{lch}}$ is the discharge through the soils $\left(\mathrm{m} \mathrm{yr}^{-1}\right)$, and $(\mathrm{Nx})_{\text {soil }}$ is the concentration of the nitrogen species in soil solution $\left(\mathrm{mmol} \mathrm{m}^{-3}\right)$. Provision is made in the model for additional losses of inorganic nitrogen by processes such as denitrification (but not including biotic uptake, for these processes see below). The magnitude and timing of these additional losses may be specified a priori, or they may be linked to concentrations of $\mathrm{NO}_{3}$ or $\mathrm{NH}_{4}$ in soil solution using firstorder reaction kinetics.

Soil adsorption of inorganic nitrogen.

Both $\mathrm{NO}_{3}$ and $\mathrm{NH}_{4}$ can have adsorbed phases in the model. Adsorption of either inorganic nitrogen species is modelled as a non-linear capacity-limited process using a hyperbolic equation:

$$
\mathrm{E}_{\mathrm{Nx}}=\mathrm{K}_{\mathrm{mx}, \mathrm{Nx}, \mathrm{ads}} \times \frac{(\mathrm{Nx})_{\text {soil }}}{\left(\mathrm{K}_{\mathrm{hlf}, \mathrm{Nx}, \mathrm{ads}}+(\mathrm{Nx})_{\text {soil }}\right)}
$$

where $E_{N x}$ is the amount of exchangeable nitrogen species on the soil matrix $\left.(\mathrm{mmol} \mathrm{kg})^{-1}\right),(\mathrm{Nx})_{\text {soil }}$ is. the concentration of the inorganic nitrogen species in soil solution $\left(\mathrm{mmol} \mathrm{m}^{-3}\right), \mathrm{K}_{\mathrm{mx}, \mathrm{Nx} \text {,ads }}$ is the maximum adsorption capacity of the soil for the nitrogen species ( $\mathrm{mmol}$ $\mathrm{kg}^{-1}$ ), and $\mathrm{K}_{\mathrm{hlf}, \mathrm{Nx} \text {,ads }}$ is the concentration of the nitrogen species in soil solution at which the amount of exchangeable nitrogen equals one-half of the maximum capacity $\left(\mathrm{mmol} \mathrm{m}{ }^{-3}\right)$. Separate equations are used for $\mathrm{NO}_{3}$ and $\mathrm{NH}_{4}$ in the model (Table 1). Adsorption of either $\mathrm{NH}_{4}$ or $\mathrm{NO}_{3}$ can be turned off in the model by setting the maximum capacity for that species to zero. 


\section{Nitrification.}

Nitrification, microbially mediated transformation of $\mathrm{NH}_{4}$ to $\mathrm{NO}_{3}$, is represented in the model by a first-order reaction. The rate of loss of $\mathrm{NH}_{4}$ (equal to the rate of production of $\mathrm{NO}_{3}$ ) is given by the product of a rate constant and the concentration of $\mathrm{NH}_{4}$ at each time step:

$$
\mathrm{FN}_{\text {nit }}=\mathrm{NIT} \times\left(\mathrm{NH}_{4}\right)_{\text {soil }} \times \mathrm{SPV}
$$

where $\mathrm{FN}_{\text {nit }}$ is the nitrification loss of $\mathrm{NH}_{4}$ (or gain of $\left.\mathrm{NO}_{3}, \mathrm{mmol} \mathrm{m}^{-2} \mathrm{yr}^{-1}\right)$, $\left(\mathrm{NH}_{4}\right)_{\text {soil }}$ is the concentration of $\mathrm{NH}_{4}$ in soil solution $\left(\mathrm{mmol} \mathrm{m} \mathrm{m}^{-3}\right)$, NIT is the nitrification rate constant $\left(\mathrm{yr}^{-1}\right)$, and SPV is the pore volume per unit area of the soils $(\mathrm{m})$.

\section{Uptake of inorganic nitrogen by the plant compartment}

Uptake by the plant compartment is modelled as nonlinear processes that depend on soil solution concentrations of the inorganic nitrogen species being utilized. The equation is hyperbolic (a typical Michaelis-Menten uptake process):

$$
\mathrm{FNx}_{\mathrm{upt}, \mathrm{plt}}=\mathrm{K}_{\mathrm{mx}, \mathrm{Nx}, \mathrm{plt}} \times \frac{(\mathrm{Nx})_{\text {soil }}}{\left(\mathrm{K}_{\mathrm{hlf}, \mathrm{Nx}, \mathrm{plt}}+(\mathrm{Nx})_{\mathrm{soil}}\right)}
$$

where $\mathrm{FNx}_{\mathrm{upt} \text {,plt }}$ is the uptake flux of the inorganic nitrogen species by the plant compartment $\left(\mathrm{mmol} \mathrm{m}^{-2} \mathrm{yr}^{-1}\right)$, $(\mathrm{Nx})_{\text {soil }}$ is the concentration of the inorganic nitrogen species in soil solution $\left(\mathrm{mmol} \mathrm{m}^{-3}\right), \mathrm{K}_{\mathrm{mx} \text {,Nx,plt }}$ is the maximum uptake rate $\left(\mathrm{mmol} \mathrm{m}^{-2} \mathrm{yr}^{-1}\right)$, and $\mathrm{K}_{\mathrm{hlf}, \mathrm{Nx} \text {,plt }}$ is the half-saturation constant (the concentration of inorganic nitrogen species at which plant uptake proceeds at half of the maximum rate; $\mathrm{mmol} \mathrm{m}^{-3}$ ). Separate equations are included for $\mathrm{NH}_{4}$ and $\mathrm{NO}_{3}$ uptake by the plant compartment (Table 1).

The conceptual basis of the model requires that plant uptake be regulated not only by the availability of inorganic nitrogen in soil solution, but also by the productivity of the plant compartment and by the internal nitrogen status of the plant compartment. These additional controls (or feedback) on the uptake process are implemented in the model by making the maximum uptake rate and the half-saturation constant in the above uptake equation into time-varying parameters that are functions of the carbon and nitrogen characteristics of the plant compartment.

The maximum uptake rate of the plants is assumed to be proportional to the carbon productivity of the plants. At zero productivity, there should be no uptake of inorganic nitrogen regardless of the inorganic nitrogen concentrations in soil solution or the internal nitrogen status of the plants. As carbon productivity increases, the maximum uptake rate of inorganic nitrogen should also increase. This relationship is incorporated in the model using a linear equation:

$$
\mathrm{K}_{\mathrm{mx}, \mathrm{Nx}, \mathrm{plt}}=\mathrm{FC}_{\mathrm{npp}} \times \mathrm{M}_{\mathrm{Nx}, \mathrm{plt}}
$$

where $\mathrm{FC}_{\mathrm{npp}}$ is the net carbon primary productivity of the plants ( $\mathrm{mmol} \mathrm{m} \mathrm{yr}^{-1}$ ), and $\mathrm{M}_{\mathrm{Nx} \text {,plt }}$ is a unitless factor determining the maximum number of moles of nitrogen incorporated into plant biomass per mole of carbon incorporated into biomass when plant uptake of nitrogen is not limited by the concentration of inorganic nitrogen in soil solution and the internal nitrogen content of the plant compartment is near zero. Obviously, this factor has no real meaning and cannot be measured directly. It therefore becomes a calibration parameter that must be adjusted empirically when the model is fitted to the data from a given site. The procedure for adjusting the parameter and the effect the parameter has on model functioning is discussed below.

The half-saturation constant of the uptake equation controls the steepness of the uptake curve for a given value of the maximum uptake rate. For small values of $\mathrm{K}_{\mathrm{hlf}, \mathrm{Nx} \text {,plt }}$, uptake will proceed at rates near to $\mathrm{K}_{\mathrm{mx}, \mathrm{Nx} \text {,plt }}$

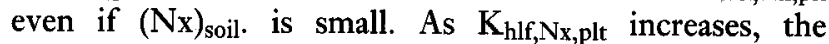
actual uptake rate will decline for the same values of $\mathrm{K}_{\mathrm{mx}, \mathrm{Nx}, \mathrm{plt}}$ and $(\mathrm{Nx})_{\text {soil }}$. Thus, $\mathrm{K}_{\mathrm{hlf}, \mathrm{Nx} \text {,plt }}$ can be thought of as controlling the efficiency of uptake - low $K_{\text {hlf,Nx,plt }}$ produces high uptake efficiency while high $K_{h l f, N x, p l t}$ produces low uptake efficiency. The conceptual model assumes that the internal nitrogen status of the plant compartment should control the efficiency of nitrogen uptake-high values of the $\mathrm{C}: \mathrm{N}$ ratio produce high uptake efficiency, low values of $\mathrm{C}: \mathrm{N}$ result in decreased uptake efficiency. The mathematical model, therefore, incorporates an inverse relationship between the halfsaturation constant of the uptake equation and the C:N ratio of the plant compartment. The relationship is assumed to be exponential (to avoid negative values):

$$
\mathrm{K}_{\mathrm{hl}, \mathrm{Nx}, \mathrm{plt}}=\mathrm{K}_{0} \times \exp \left(\frac{\mathrm{C}: \mathrm{N}_{0, \mathrm{plt}}-\mathrm{C}: \mathrm{N}_{\mathrm{plt}}}{\mathrm{S}_{\mathrm{Nx}, \mathrm{plt}}}\right)
$$

where $\mathrm{C}: \mathrm{N}_{\mathrm{plt}}$ is the simulated $\mathrm{C}: \mathrm{N}$ ratio of the plant compartment at any time in the simulation, $\mathrm{C}: \mathrm{N}_{0, \mathrm{plt}}$ is the target $\mathrm{C}: \mathrm{N}$ ratio of the plant compartment, $\mathrm{K}_{0}$ (mmol $\mathrm{m}^{-3}$ ) is the value of the half saturation constant when the simulated C:N ratio equals the target $\mathrm{C}: \mathrm{N}$ ratio, and $S_{N x, p l t}$ is a unitless factor controlling the steepness of the

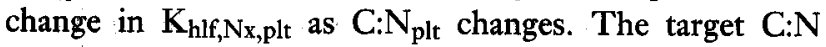
ratio for the plant compartment is specified as an input to the model. The value of $\mathrm{K}_{0}$ is set to an arbitrarily large number (e.g. $1000 \mathrm{mmol} \mathrm{m}{ }^{-3}$ ) to produce a low uptake efficiency when C: $\mathrm{N}_{\text {plt }}$ is equal to C: $\mathrm{N}_{0, p l t}$. The steepness parameter $S_{\mathrm{Nx} \text {,plt }}$ is adjusted to control the closeness with which the simulated C:N ratio. tracks the target value (assuming inorganic nitrogen is available in solution). Large values of $S_{\mathrm{Nx}, \mathrm{plt}}$ cause the simulation to track closely. Small values will allow the plant C:N to 
depart significantly from the target before significant changes in uptake occur. Separate uptake equations are used for $\mathrm{NH}_{4}$ and $\mathrm{NO}_{3}$ in the model (Table 1). If the parameters in the equations for $\mathrm{NH}_{4}$ and $\mathrm{NO}_{3}$ are set to different numerical values, preferential uptake of one species of inorganic nitrogen can be simulated.

Immobilization of inorganic nitrogen by soil microorganisms.

Soil microbial processes affect inorganic nitrogen through immobilization of $\mathrm{NH}_{4}$ and $\mathrm{NO}_{3}$ and through mineralization of organic matter to produce $\mathrm{NH}_{4}$ (ammonification). The immobilization equations presented here are for the LOM compartment (Fig. 1). Similar equations are used in the model for the ROM compartment (Table 1). Immobilization is modelled as a non-linear process that depends on the soil solution concentrations of inorganic nitrogen in a manner similar to that used for plant uptake (equation 5):

$$
\mathrm{FNx}_{\mathrm{upt}, \mathrm{LOM}}=\mathrm{K}_{\mathrm{mx}, \mathrm{Nx}, \mathrm{LOM}} \times \frac{(\mathrm{Nx})_{\text {soil }}}{\left(\mathrm{K}_{\mathrm{hl}, \mathrm{Nx}, \mathrm{LOM}}+(\mathrm{NX})_{\text {soil }}\right)}
$$

where $\mathrm{FNx}_{\mathrm{upt}, \mathrm{LOM}}$ is the uptake of the inorganic nitrogen species by the LOM compartment $\left(\mathrm{mmol} \mathrm{m}^{-2} \mathrm{yr}^{-1}\right.$ ), $(\mathrm{Nx})_{\text {soil }}$ is the concentration of the inorganic nitrogen species in soil solution $\left(\mathrm{mmol} \mathrm{m} \mathrm{m}^{-3}\right), \mathrm{K}_{\mathrm{mx}, \mathrm{Nx}, \mathrm{LOM}}$ is the maximum uptake rate $\left(\mathrm{mmol} \mathrm{m}^{-2} \mathrm{yr}^{-1}\right)$, and $\mathrm{K}_{\mathrm{hlf}, \mathrm{Nx}, \mathrm{LOM}}$ is the concentration of the inorganic nitrogen species at which immobilization proceeds at half of the maximum rate $\left(\mathrm{mmol} \mathrm{m}^{-3}\right)$. Separate equations are included for $\mathrm{NH}_{4}$ and $\mathrm{NO}_{3}$ uptake by the LOM compartment (Table 1).

Immobilization is assumed to be the result of microbial utilization of inorganic nitrogen from soil solution for growth. This growth depends on energy derived from decomposition of organic matter. Immobilization is assumed, therefore, to be proportional to the secondary productivity of the microbes (as measured by decomposition and assuming a constant microbial substrate use efficiency) in much the same way as plant uptake is proportional to the net primary productivity of the plants. This suggests that $\mathrm{K}_{\mathrm{m}, \mathrm{Nx}, \mathrm{LOM}}$ and $\mathrm{K}_{\mathrm{s}, \mathrm{Nx}, \mathrm{LOM}}$ in Equation (8) may be parameterized for immobilization in a manner similar to their parameterization for plant uptake.

Specifically, the maximum uptake rate of the LOM compartment is assumed to be proportional to the carbon decomposition of that compartment:

$$
\mathrm{K}_{\mathrm{mx}, \mathrm{Nx}, \mathrm{LOM}}=\mathrm{FCdcmp}, \mathrm{LOM} \times \mathrm{MNx}, \mathrm{LOM}
$$

where $F_{d c m p, L O M}$ is the carbon decomposition of the LOM compartment ( $\mathrm{mmol} \mathrm{m}^{-2} \mathrm{yr}^{-1}$ ), and $\mathrm{M}_{\mathrm{Nx}, \mathrm{LOM}}$ is a unitless factor determining the maximum number of moles of nitrogen incorporated into microbial biomass per mole of carbon decomposed. As with the parameteri- zation of the plant compartment, $\mathbf{M}_{\mathrm{Nx}, \mathrm{LOM}}$ cannot be measured directly. It becomes, therefore, a calibration parameter that must be adjusted empirically when the model is fitted to the data from a given site. The procedure for adjusting the parameter and the effect the parameter has on model functioning is discussed below.

The half-saturation constant for immobilization of inorganic nitrogen into the LOM compartment is given by:

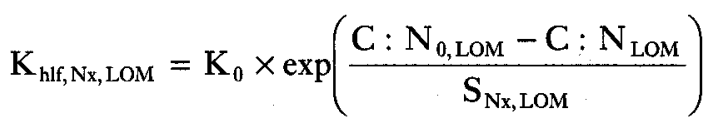

where $\mathrm{C}: \mathrm{N}_{L O M}$ is the carbon to nitrogen ratio of the LOM compartment at any time in the simulation, C: $\mathrm{N}_{0, \mathrm{LOM}}$ is the target C:N ratio of the LOM compartment, $\mathrm{K}_{0}\left(\mathrm{mmol} \mathrm{m}^{-3}\right)$ is the value of the half saturation constant when the simulated $\mathrm{C}: \mathrm{N}$ ratio of the LOM compartment equals the target $\mathrm{C}: \mathrm{N}$ ratio, and $\mathrm{S}_{\mathrm{Nx}, \mathrm{LOM}}$ is a unitless factor controlling the steepness of the change in $\mathrm{K}_{\mathrm{hlf,Nx}, \mathrm{LOM}}$ as C:N $\mathrm{N}_{\mathrm{LOM}}$ changes. These parameters are specified in the model as described for the plant compartment (equation 7). Separate uptake equations are used for $\mathrm{NH}_{4}$ and $\mathrm{NO}_{3}$ in the model (Table 1). If the parameters in the equations for $\mathrm{NH}_{4}$ and $\mathrm{NO}_{3}$ are set to different numerical values, preferential immobilization of one species of inorganic nitrogen can be simulated.

\section{Mineralization by soil microorganisms.}

Mineralization represents the release of inorganic nitrogen from organic matter (Fig. 1). The mineralization product is $\mathrm{NH}_{4}$ and is produced by both the LOM and ROM compartments. Mineralization is proportional to the carbon decomposition flux and the $\mathrm{C}: \mathrm{N}$ ratio of the LOM or ROM compartment at the time the decomposition occurs:

$$
\mathrm{FN}_{\text {min, LOM }}=\frac{\mathrm{FC}_{\mathrm{dcmp}, \mathrm{LOM}}}{\mathrm{C}: \mathrm{N}_{\text {LOM }}}
$$

where $\mathrm{FN}_{\text {min,LOM }}$ is the flux of inorganic nitrogen (as ammonium ion) produced by mineralization from the LOM compartment ( $\mathrm{mmol} \mathrm{m} \mathrm{yr}^{-1}$ ), $\mathrm{FC}_{\mathrm{dcmp}, \mathrm{LOM}}$ is the carbon decomposition rate of the LOM compartment $\left(\mathrm{mmol} \mathrm{m} \mathrm{yr}^{-1}\right)$, and C: $\mathrm{N}_{\mathrm{LOM}}$ is the currently simulated C:N ratio of the compartment. The model provides an option for the user to specify a different value (C: $\left.N_{\mathrm{dcmp}}, \mathrm{LOM}\right)$ of the carbon-to-nitrogen ratio for use in equation 11 in place of the currently simulated value (C: $\mathrm{N}_{\mathrm{LOM}}$ ), This option would be invoked if the material being decomposed were assumed to have a significantly different C:N ratio than that of the bulk compartment (for instance, preferential decomposition of substrate with a lower $\mathrm{C}: \mathrm{N}$ ratio). A similar equation is used in the model for mineralization from the ROM compartment (Table 1). 


\section{Biomass transfers of organic nitrogen.}

Several translocations of organic nitrogen occur in the model as a result of biomass transfers between compartments. These transfers are storage of organic nitrogen in wood, loss of organic nitrogen through export from ROM, litter (transfer from plants to LOM) and decay (transfer from LOM to ROM). The model is configured to use either of two $\mathrm{C}: \mathrm{N}$ ratios to calculate the flux of organic nitrogen given the input carbon flux along the pathway (Fig. 1). The two possible C:N ratios are the $\mathrm{C}: \mathrm{N}$ of the donor compartment or a user specified C:N. Most often the C:N used for wood production and export (losses to long-term storage, Fig. 1) are user specified because the C:N of wood and peat (for instance) are usually very different from the C:N of the donor compartment. While this may also be the case for litter production in some ecosystems, long-term mass balance considerations usually require that the C:N used for litter and decay in the model be those of the donor compartments (to prevent build-up or depletion of nitrogen in the donor compartments). The form of the equations used for these transfers can be illustrated using the wood and litter production functions (all equations are listed in Table 1):

$$
\begin{aligned}
& \mathrm{FN}_{\mathrm{wd}}=\frac{\mathrm{FC}_{\mathrm{wd}}}{\mathrm{C}: \mathrm{N}_{\mathrm{wd}}} \\
& \mathrm{FN}_{\mathrm{lit}}=\frac{\mathrm{FC}_{\mathrm{lit}}}{\mathrm{C}: \mathrm{N}_{\mathrm{plt}}}
\end{aligned}
$$

where $\mathrm{FN}_{\mathrm{wd}}$ and $\mathrm{FN}_{\mathrm{lit}}$ are the organic nitrogen fluxes in wood and litter production ( $\left.\mathrm{mmol} \mathrm{m} \mathrm{m}^{-2} \mathrm{yr}^{-1}\right), \mathrm{FC}_{\mathrm{wd}}$ and $\mathrm{FC}_{\text {lit }}$ are the carbon fluxes in wood and litter production (mmol $\mathrm{m}^{-2} \mathrm{yr}^{-1}$ ), C: $\mathrm{N}_{\mathrm{wd}}$ in equation 12 is a user specified C:N ratio that draws nitrogen from the plant compartment for wood production at different (usually much higher) value than that of the bulk plant compartment, and C: $\mathrm{N}_{\text {plt }}$ in equation 13 is the currently simulated $\mathrm{C}: \mathrm{N}$ ratio of the plant compartment.

\section{Nitrogen mass balance.}

Mass balance is maintained in the model by writing the differential equations for the rate of change of the carbon and nitrogen state variables using the process equations derived above. Mass balances for the organic compartments require that the rates of change of carbon or nitrogen in the compartments be equal to the sources minus the losses for the compartments at any time in the simulation. Using the plant compartment as an example:

$$
\begin{gathered}
\frac{d}{d t} \mathrm{C}_{\mathrm{plt}}=\mathrm{FC}_{\mathrm{npp}}-\mathrm{FC}_{\mathrm{lit}}-\mathrm{FC}_{\mathrm{wd}} \\
\frac{d}{d t} \mathrm{~N}_{\mathrm{plt}}=\mathrm{FNH}_{4_{\mathrm{upp}, \mathrm{fl}}}+\mathrm{FNO}_{3_{\mathrm{upppht}}}-\mathrm{FN}_{\mathrm{lit}}-\mathrm{FN}_{\mathrm{wd}}
\end{gathered}
$$

where $\mathrm{C}_{\mathrm{plt}}$ and $\mathrm{N}_{\mathrm{plt}}$ are organic carbon and nitrogen amounts in the plant compartment $\left(\mathrm{mmol} \mathrm{m}{ }^{-2}\right), \mathrm{FC}_{\mathrm{wd}}$, $\mathrm{FC}_{\mathrm{lit}}, \mathrm{FN}_{\mathrm{wd}}$, and $\mathrm{FN}_{\mathrm{lit}}$ are fluxes of carbon and nitrogen in wood and litter production (as defined in equations 12 and 13), and $\mathrm{FC}_{\mathrm{npp}}, \mathrm{FNH}_{4 \text { upt,plt and }} \mathrm{FNO}_{3 \text { upt,plt are the }}$ primary production and inorganic nitrogen uptake fluxes of the plant compartment (as defined in equations 5, 6 and 7). Equations for all organic compartments are given in Table 1.

Mass balances for the inorganic nitrogen species require that the rate of change of ammonium or nitrate in the soils of the ecosystem be equal to the sources minus the losses at any time in the simulation. The situation is complicated somewhat by the fact that both species have a potential adsorbed phase. For example, the total ammonium ion present in the soils is written as:

$$
\mathrm{NH}_{4 \text { tot }}=\mathrm{SPV} \times\left(\mathrm{NH}_{4}\right)_{\text {soil }}+\mathrm{SMS} \times \mathrm{E}_{\mathrm{NH}_{4}}
$$

where $\mathrm{NH}_{4 \text { tot }}$ is the total ammonium in the soils $(\mathrm{mmol}$ $\left.\mathrm{m}^{-2}\right),\left(\mathrm{NH}_{4}\right.$ soil $_{\text {is }}$ is the concentration of ammonium in soil solution $\left(\mathrm{mmol} \mathrm{m}^{-3}\right)$, SPV is the pore volume per unit area of the soils (m), $\mathrm{E}_{\mathrm{NH} 4}$ is the amount of exchangeable ammonium on the soil matrix $\left(\mathrm{mmol} \mathrm{kg}^{-1}\right.$; see equation 3), and SMS is the mass of soil per unit area $\left(\mathrm{kg} \mathrm{m}^{-2}\right)$. The rate of change of total ammonium in the soil solution is equal to the sum of all input fluxes of ammonium (deposition and mineralization) minus the output fluxes of ammonium (nitrification, uptake and leaching). Differentiating equation 16 with respect to time, rearranging, and identifying the appropriate ammonium source and loss fluxes yields the $\mathrm{NH}_{4}$ mass balance equation:

$$
\begin{aligned}
\frac{d}{d t}\left(\mathrm{NH}_{4}\right)_{\text {soil }}=-\frac{\mathrm{SML}}{\mathrm{SPV}} & \times \frac{d}{d t} \mathrm{E}_{\mathrm{NH}_{4}} \\
& +\sum \text { Sources }-\sum \text { Losses }
\end{aligned}
$$

where

$$
\begin{aligned}
& \Sigma \text { Sources }=\mathrm{FNH}_{4_{\text {dep }}}+\mathrm{FN}_{\text {min, LOM }}+\mathrm{FN}_{\text {min, ROM }} \\
& \Sigma \text { Losses }=\mathrm{FN}_{\text {nit }}+\mathrm{FNH}_{4_{\mathrm{cch}}}+\mathrm{FNH}_{4_{\text {wep }, \text { IOM }}}+\mathrm{FNH}_{4_{\text {wot ROM }}}
\end{aligned}
$$

and $\mathrm{FN}$ has been defined in equations $1,2,4,5,8$ and 11. A similar approach yields the mass balance equation for $\mathrm{NO}_{3}$ (Table 1).

\section{MODEL IMPLEMENTATION AND CALIBRATION}

The model is designed for annual or seasonal resolution and a simulation period of 50 to 150 years. The state variables in the model are, of course, time variable. Some of the parameters (such as the maximum uptake rates for inorganic nitrogen) are also time variable due to the nature of their definition as functions of state variables. 
Other parameters, such as the target C:N ratios of the compartments, will usually be true constants. Provision has been made, however, for these 'constant' parameters to be changed during the course of a simulation if the assumptions of the simulation require a change (for instance, land use changes involving introduction of a new species of plant may require a new target C:N value for the plant compartment). In general, the inputs required for the model are: 1) temporal sequences of carbon fluxes and pools; hydrological discharge through the soils, and external sources of inorganic nitrogen; 2) initial conditions (amounts of carbon and nitrogen) for each compartment including the soil solution; and 3) a number of constants to specify the nitrogen dynamics of the organic compartments and the characteristics of the soils, Qutputs from the model include: 1) concentrations and fluxes of $\mathrm{NO}_{3}$ and $\mathrm{NH}_{4}$ in soil water and runoff; 2) total nitrogen contents of the organic and inorganic compartments; 3) $\mathrm{C}: \mathrm{N}$ ratios of the aggregated plant and soil compartments; and 4) magnitudes of important processes in the nitrogen cycle of the simulated system (i.e., uptake, gross and net mineralization, and immobilization). The inputs, state variables and constants are summarized in Tables 1 and 2.

The model is implemented by solving the mass balance equations in Table 1 . The equations are in many cases non-linear, however, so a numerical (rather than explicit) solution scheme has been adopted that depends on frequent re-linearization. That is, many parameters affecting state variables depend on the current values of those same state variables. Therefore, even if the model is providing annual or seasonal resolution, the time steps used in the simulation are much smaller than yearly or monthly. At the end of each step, the parameters depending on state variables are 'updated' with the current value of the state variables. The updated parameters are then used to simulate new values of the state variables for the next update in an iterative procedure.

A number of the parameters in the model cannot be measured directly (either as a result of the level of aggregation or because of difficulty in making the measurements). These parameters have been designated as calibration parameters for the model. Their values are selected to provide a good fit to current observations on the system of interest (as described in the conceptual description of the model). In particular, the parameters used in the uptake equations $\left(\mathrm{M}_{\mathrm{Nx}, \mathrm{plt}}\right.$, equation 6 and $\mathrm{S}_{\mathrm{Nx} \text {,plt, }}$ equation 7) are used to control the relative effectiveness of any organic compartment in obtaining inorganic nitrogen from the soil solution. To illustrate, consider the mass balance equation for ammonium (equation 17) and, to simplify, consider that the only source is constant deposition (no mineralization), that the only losses are leaching and plant uptake (no immobilization by LOM or ROM), and that there is no adsorption by the soils. Under these assumptions equation 17 combined with equations 2 and 5 becomes:

$$
\begin{aligned}
\frac{d}{d t}\left(\mathrm{NH}_{4}\right)_{\text {soil }}=\mathrm{FNH}_{4_{\text {dep }}}-\left(\mathrm{NH}_{4}\right)_{\text {soil }} \times \\
\left(\frac{\mathrm{Q}_{\text {lch }}}{\mathrm{SPV}}+\frac{\mathrm{K}_{\mathrm{mx}, \mathrm{NH}_{4}, \mathrm{plt}}}{\left(\mathrm{SPV} \times\left(\mathrm{K}_{\mathrm{hl}, \mathrm{NH}_{4}, \mathrm{plt}}+\left(\mathrm{NH}_{4}\right)_{\mathrm{soil}}\right)\right)}\right)
\end{aligned}
$$

The two terms in the brackets on the right hand side of equation 18 each have units of $\mathrm{yr}^{-1}$ and can be considered the rate constants of hydrological leaching and plant uptake respectively. It can be shown that, in the numerical solution to the equation, the term having the larger rate constant (smaller turnover time) will become the dominant flux for ammonium ion. The larger the difference, the larger the $\mathrm{NH}_{4}$ flux in the preferred pathway. This suggests a direct dynamic 'competition' between biotic and abiotic processes and is a unique feature of the MERLIN madel.

Equation 18 can also be used to illustrate the calibration procedure for the model. Given values of SPV and

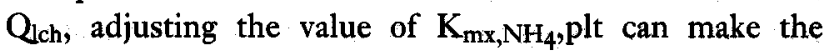
plants better or worse 'competitors' for $\mathrm{NH}_{4}$ If the maximum rate is too large, the plants become too rich in nitrogen and the soil leachate concentration will be too low. If the maximum rate is too low, the plants will become impoverished with respect to nitrogen and the soil leachate concentration will be too large. For a given carbon flux, the maximum rate is a function of the cali-

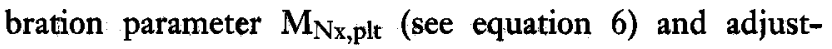

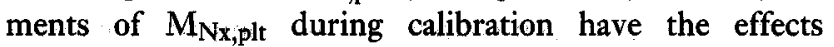
described above. Note that $\left(\mathrm{NH}_{4}\right.$ )oil, a state variable, also appears in the term for the plant uptake rate constant. This is one of the non-linearities inherent in the model and is accounted for by re-linearizing the equations frequently during solution. The presence of the state variable in the term can affect the calibration sensitivity, however, and cause it to vary during the simulation. Additional terms, (and rate constants) will appear in equation 18 as nitrification, immobilization by LOM and by ROM and soil adsorption are added. Each new process will 'compete' for $\mathrm{NH}_{4}$ and will have a calibration parameter that can be adjusted to achieve simultaneous fits to all nitrogen pools and the soil leachate concentration. Similar calibration adjustments can be made using the parameters affecting uptake, immobilization and adsorption of nitrate.

\section{Simulation examples}

The functioning of the model can best be demonstrated in a series of speculative simulation exercises. These exercises are hypothetical in that the values of parameters and variables used in the model are not observed on a real system. The values are chosen to be approximately those of forested systems in northern Europe, but the dynamics of the system are simplified in order to isolate 
and demonstrate the effects of individual variables in the model. Two types of simulation are presented: 1) simulations using constant carbon dynamics (i.e., steady state ecosystems); and 2) simulations using time varying carbon dynamics (i.e., land use changes). Each of these types of simulations was driven by three inorganic nitrogen input sequences. The resultant six simulations demonstrate the sensitivity of the model to carbon and nitrogen inputs. An application of the model to a forested site in Wales where the nitrogen inputs were manipulated is described in Enmett at al (In ypress) which also provides a calibration/validation exercise using observed data.

The same soil parameters were used for all simulations described below (depth $1.0 \mathrm{~m}$; porosity 0.5 ; bulk density $1000 \mathrm{~kg} \mathrm{~m}^{-3}$; adsorption of $\mathrm{NH}_{4}$-maximum capacity 50 mmol kg$~^{-1}$, half-saturation constant $50 \mathrm{mmol} \mathrm{m}$; no adsorption of $\mathrm{NO}_{3}$; nitrification rate constant $1000 \mathrm{yr}^{-1}$; discharge $1.0 \mathrm{~m} \mathrm{yr}^{-1}$ ). All simulations used the C.N ratio of the donor compartment for calculating biomass transfers and decomposition. None of the sintiulations included wood production; organic matter expert from ROM or denitrification. All simulations used the same values of the uptake and inmobilization parameters (see Table 2; target $\mathrm{C}: \mathrm{N}$ ratios-plant $=56, \mathrm{LOM}=24$, $\mathrm{ROM}=15$; maximum $\mathrm{NH}_{4}$ or $\mathrm{NO}_{3}$ uptake per unit carbon- plant $=.02, \mathrm{LOM}=.04, \mathrm{ROM}=.04$; steepness factor-plant, LOM and ROM $=0.5$; upper limit of half-saturation parameter-plant, LOM and ROM = 1000). Initial nitrogen contents of the compartments were calculated to give the same initial C:N ratio in a given compartment for each simulation (plant $=60 ; \mathrm{LOM}=$ 28; $\mathrm{ROM}=18$ ): Carbon pools and fluxes and inorganic nitrogen inputs were varied among the simulations and are described below.

\section{SIMULATIONS USING CONSTANT CARBON DYNAMICS (DEPOSITION EFFECTS)}

Three simulations were performed in which the pools and fluxes of carbon were held constant throughout the simulations and inputs of inonganio mitrogen were varied to extmine the responses to different deposition regimes. The constant carbon pools and fluxes for these simulations were: plant compartment biomass $100 \mathrm{~mol} \mathrm{~m}^{-2}$; LOM compartment biomass $150 \mathrm{~mol} \mathrm{~m}^{-2}$; ROM compartment biomass $1000 \mathrm{~mol} \mathrm{~m}^{-2} ;$ litter production $15 \mathrm{~mol}$ $\mathrm{m}^{-2} \mathrm{yr}^{-1}$; LOM decomposition $7.5 \mathrm{~mol} \mathrm{~m}^{-2} \mathrm{yr}^{-1}$; and ROM decomposition $7.5 \mathrm{~mol} \mathrm{~m}^{-2} \mathrm{yr}^{-1}$; Simulations were run for 60 years. The first 10 years were steady state with respect to all inputs and variables. Starting at year 11 in the simulation, inorganic nitrogen was added in thre patternis to the system (Fig 2A), 1) a pulse inputa large increase lasting only one year; 2 ) a step input - a moderate increase in year 11 followed by constant input at the new level for the remaining 50 years; and 3 ) a ramp input-a linear increase starting in year 11 and continuing at the same rate of increase for the remaining 50 years of the simulation. The integral under each input sequence (the total inorganic nitrogen added) was the same in all three simulations $\left(5000 \mathrm{mmol} \mathrm{m} \mathrm{m}^{-2}\right)$. The nitrogen was added as equal amounts of nitrate and
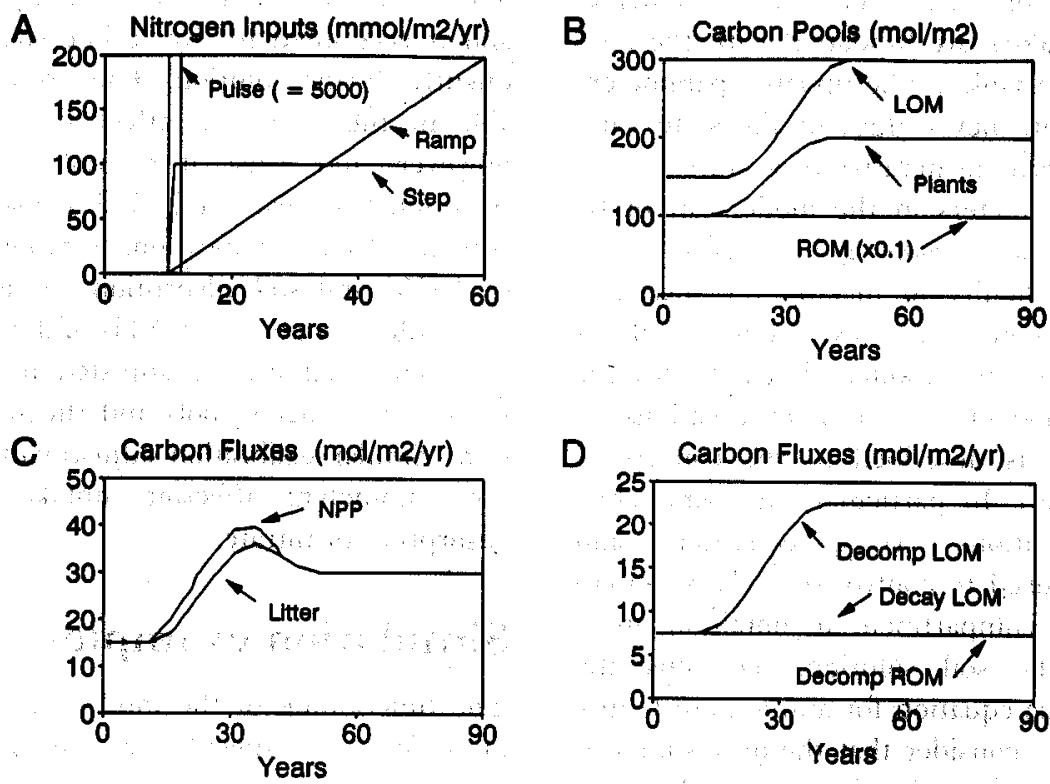

Fig. 2 Carbon and nitrogen sequences used for the simulations described in the text: $A$ ) the nitrogen input sequences for the simulations mith constant carbon dynamics; $B$ ) the sequences of carbon standing crop for the land use change simulations-the $R O M$ value is scaled to fit on the plot; the actual value is $1000 \mathrm{~mol} \mathrm{~m}$; C) the net prodiction and litter fluxes for the land use change simulations; and D) the decomposition and decay fluxes for the land use change simulations. 
ammonium ions $\left(2500 \mathrm{mmol} \mathrm{m}^{-2}\right.$ each). The outputs are presented as changes in state variables and fluxes from the initial steady state conditions as a result of the modified deposition (value in reference year minus value in year 1 ).

Results for input/output fuxes and nitrogen pools (depasition effects)

The pulse input produced an immediate response in nitrogen leaching with about $30 \%$ of the nitrogen input lost in the following year (Fig. $3 \mathrm{~A}$ ). This high nitrogen leaching was, however, short lived and the output flux rapidly declined such that within about 10 years the system output reverted to its steady state level. The important controlling mechanism on nitrogen leaching was initially the ability of the soil to adsorb $\mathrm{NH}_{4}$ (Fig. 3B). As the adsorbed nitrogen was released, other processes increased in importance. Plant uptake and immobilization by soil microbial processes resulted in a re-partitioning of the added nitrogen over the next 30 years into the LOM and ROM compartments. The plant compartment did
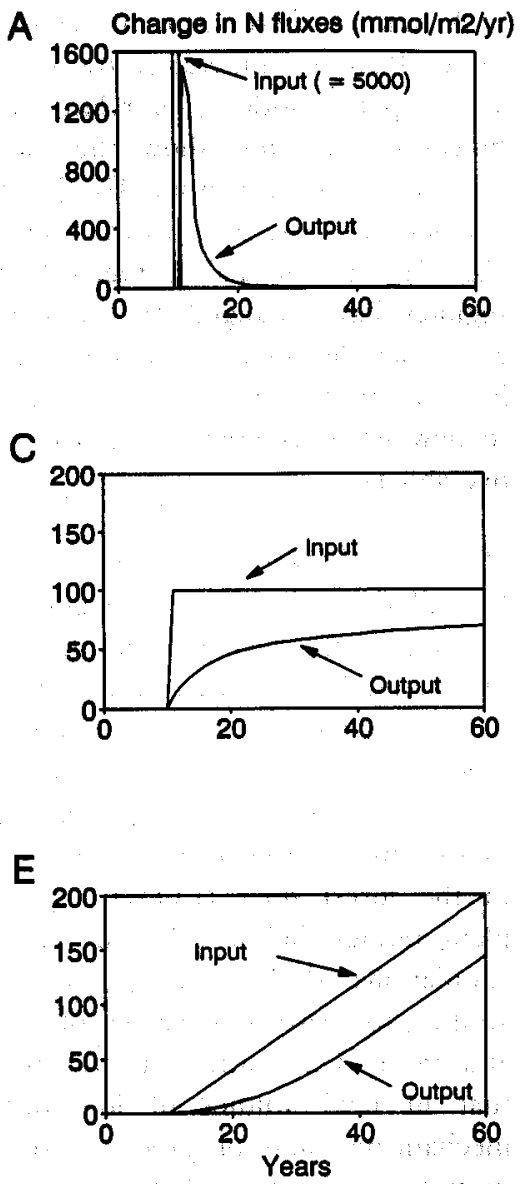

not act as a long-term store of nitrogen, but behaved as a small pool with a rapid turnover. The ultimate storage location for the bulk of the nitrogen retained in the system was the ROM compartment. This behaviour is qualitatively consistent with observations of nitrogen leaching following forest fertilization (Hartiman 1978) and of nitrogen partitioning following fertilizer application using ${ }_{15}^{15} \mathrm{~N}$ as a tracer (Heilman et al. 1982, Nambiar and Bowẹn 1986, Hulm and Killham 1990, Preston and Mead 1994):

In nesponse a step change in nitrogen input, nitrogen leaching increased inamediately and then levelled off in the long term (Fig. 3G), Both the adsorbed phase and the LOM compartment were important in sequestering nitrogen in this simulation and showed a qualitatively similar shape of response (Fig. 3D).. The ultimate sink for the added nitrogen, however, was again the ROM compartment and this pool increased rapidly and steadily. Step changes in nitrogen inputs have been initiated at several sites in Europe as part of the NITREX project (Wright and van Breemen 1995) in an attempt to
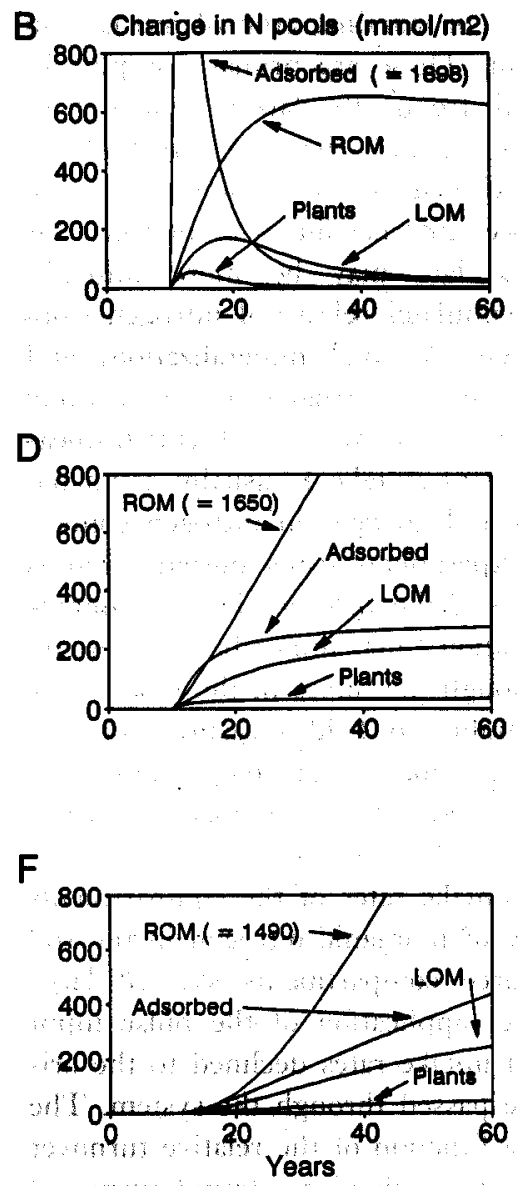

Fig. 3 Changes in the simulated values of the nitrogen input/output fluxes $(A, C$ and $E$ ) and the nitrogen contents of the organic compartments $(B, D$ and $F)$ in response to three scenarios of inorganic nitrogen inputs: $A$ and $B$ ) pulse addition; $C$ and $D)$ step change; $E$ and $F)$ ramp increase. Changes are relative to the initial steady state conditions (first ten years of the simulations). The integral of the input (total nitrogen added) is the same in all three cases. 
determine the ecosystem controls on nitrogen leaching. Both the output response and internal nitrogen dynamics simulated by the model during the first years following the step input are at least qualitatively consistent with observations from these manipulation experiments (Wright et at. 1995, Tietema et al. 1996).

The simulated response to a ramp increase in nitrogen input closely followed that of the step response in that output flux, adsorbed phase, LOM and ROM pools increased rapidly (Figs. $3 \mathrm{E}$ and $3 \mathrm{~F}$ ). Under this scenario, however, output flux and internal $\mathrm{N}$ pools continued to increase throughout the simulation. The short time lag before the output flux began to increase is consistent with observed relatively rapid catchment responses to increased nitrogen deposition (Kahl et al. 1993, Moldan et al. 1995). The model output indicated a close relationship between nitrogen input and nitrogen leaching once leaching began and this behaviour is supported by survey data from forested systems in Europe (Dise and Wright 1995).

\section{Results for internal nitrogen fuxes (deposition effects)}

The preceding discussion focuses on the input/output fluxes and the pool sizes or standing crop of nitrogen in the simulated ecosystem. These are primary outputs of the model and there are frequently data to which these model outputs can be compared (the aggregation of the model was conceived with such comparisons in mind). The model also simulates internal fluxes of nitrogen for which comparisons to data may be more difficult. Specifically the model simulates release of nitrogen from the organic compartments ('gross' mineralization) and uptake (or immobilization) of nitrogen by the organic compartments. These internal fluxes are difficult to measure on real systems. Plant uptake is usually estimated from biomass increases and changes in nitrogen content of tissues. Incubation experiments using buried columns or bags provide estimates of the difference between immobilization and mineralization ('net' mineralization) of soil compartments. Even though the fluxes in the model may not be directly comparable to field measurements (or perhaps because they are not comparable), there is a heuristic utility in examining these simulated internal fluxes.

The changes in the uptake rates of the compartments reflected the availability of inorganic nitrogen in the soil solution in that all three compartments showed large increases in uptake after application of the pulse input (Fig. 4A). The elevated uptake rates declined to the original levels as the pulse passed through the system. The pattern of decline was a function of the relative turnover times of the compartments with plants (rapid turnover) re-establishing the steady state uptake rates before the LOM compartment, and the LOM compartment before the ROM compartment. The pulse input increased mineralization of the LOM compartment (Fig. 4B) initially but, as the nitrogen pulse passed through the system, this effect also declined. ROM mineralization increased but the effect was slower and more prolonged, reflecting the delay in nitrogen reaching the ROM compartment and its longer residence time there.

A step increase of nitrogen input to the simulated system resulted in persistent changes in the nitrogen uptake and release fluxes of the model compartments (Figs. 4C and D). Mineralization of both LOM and ROM again increased with added inorganic nitrogen but with some delay as the nitrogen was incorporated into the organic matter in each compartment. Uptake increases were more immediate and declined somewhat by year 60 . The initial steep rise in uptake was a direct result of the dependence of the uptake equations on soil solution inorganic nitrogen concentrations. The decline after the initial rise was a result of the feedback in the equation based on the $\mathrm{C}: \mathrm{N}$ ratios within the compartments. Increased uptake lowered the $\mathrm{C}: \mathrm{N}$, increasing mineralization and also lowering the uptake demand. These simulations would have settled eventually: to a steady state condition with both uptake and mineralization constant at higher values if the period of simulation had been longer.

A ramped increase of nitrogen inputs has almost the same effect on mineralization as the step addition (Fig. 4F). Uptake under this relatively slow input increase, however, does not show the pronounced initial surge caused by the step input. By the time the ramped input reaches the same level as the step input (i.e., year 60 in Fig. 4), the internal nitrogen fluxes under both input regimes have changed by the same amount. This suggests that the internal nitrogen fluxes were closely tracking the input availability of nitrogen, and that adaptation to new levels is relatively quick without large delays or overshoots.

\section{Discussion of deposition effects}

For all three deposition scenarios (with constant carbon dynamics), the responses of the compartments in terms of increased long-term storage of deposited nitrogen was ROM $>$ adsorbed $>$ LOM $>$ plants. The bulk organic and inorganic storage components were more important than the LOM and plant compartments in retaining long-term or large nitrogen inputs. In addition, storage in the forest floor (LOM) was greater than in active plant tissues. While these are the results of speculative simulations, they are based on mass balance principles applied to reasonable values of carbon pools and fluxes and tissue $\mathrm{C}: \mathrm{N}$ ratios. It may be suggested, therefore, that in field studies of long-term nitrogen retention mechanisms (and of processes disrupting these mechanisms), a major part of the field effort should be focused on the processes occurring in soil organic matter. The simulations also suggest that while the changes in the ROM, LOM and adsorbed pools may be the most important, these changes may be hard to detect in the 

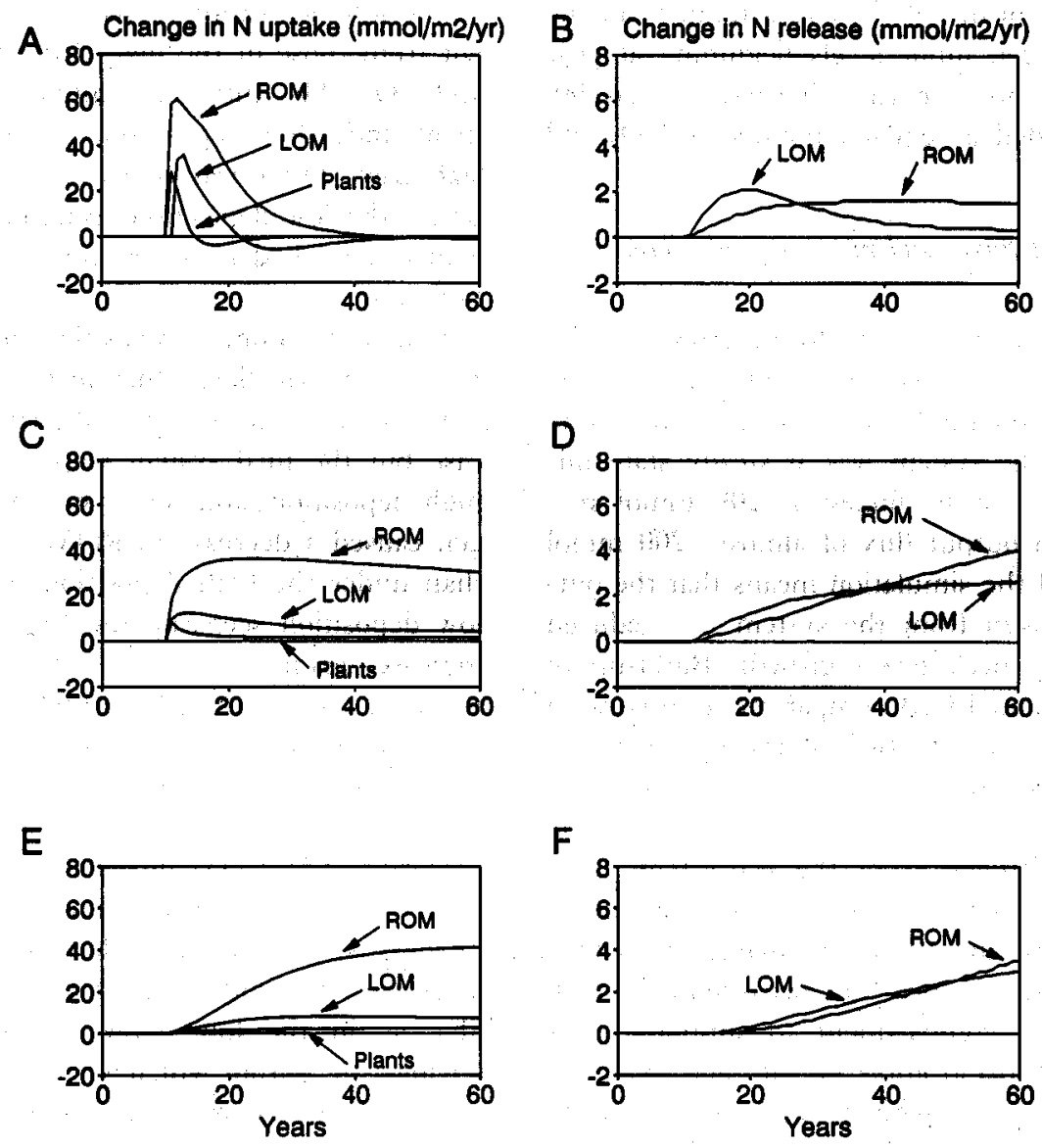

Fig. 4 Changes in simulated internal nitrogen fluxes (mineralization- $A, C, E ;$ uptake- $B, D, F$ ) in response to three scenarios of inorganic nitrogen inputs: $A$ and $B$ ) pulse addition; $C$ and D) step change; $E$ and $F$ ) ramp increase. Changes are relative to the initial steady state fluxes (first ten years of the simulations).

field for at least two reasons. First, the changes occur relatively slowly over periods of several years, and second the changes (while large in absolute terms) are small relative to the existing pool sizes.

\section{SIMULATIONS USING VARIABLE CARBON DYNAMICS (LAND USE CHANGE EFFECTS)}

Three simulations were performed in which the pools and fluxes of carbon were changed during the course of the simulation to examine land-use effects on nitrogen dynamics (afforestation for instance). The carbon pools and fluxes and sequences of changes in carbon storage and fluxes were selected to be consistent with observed and estimated values for biomass production (Miller et al. $1980 \mathrm{a}$ and $\mathrm{b}$ ), wood production (Hamilton and Christie 1971), litter production (Miller and Miller 1987, Stevens et al. 1992) and forest floor accumulation (Emmett et al. 1993) in a newly planted forest. The dynamics were calculated to be comparable with forest growth of a Yield Class 16 crop (i.e. a crop that exhibits a mean annual increment maximum of approximately 16 $\mathrm{m}^{3} \mathrm{ha}^{-1}$ ).

Simulations were run for 90 years. The first 10 years were steady state with respect to all inputs and variables. Starting at year 11 the forest growth sequence was initiated. Forest growth was simulated by doubling the carbon pools and litter flux, such that the plant compartment increased from $100-200 \mathrm{~mol} \mathrm{C} \mathrm{m}^{-2}$, the LOM compartment increased from 150 to $300 \mathrm{~mol} \mathrm{C}$ $\mathrm{m}^{-2}$, and the litter flux increased from 15 to $30 \mathrm{~mol} \mathrm{C}$ $\mathrm{m}^{-2} \mathrm{yr}^{-1}$ (Figs 2B and 2C). Net primary productivity necessarily increased rapidly in the early stages of forest growth (NPP in Fig. 2C). To reach pool size stability at the higher levels following forest growth, a three-fold increase in decomposition of the LOM compartment was needed to balance the increased flux of litter (Fig. 2D).. The pool size and the decomposition rate of the ROM compartment were both held constant (Figs. 2B and 2D).

This pattern of land-use change was simulated under three regimes of inorganic nitrogen input: 1) constant high nitrogen input $\left(200 \mathrm{mmol} \mathrm{m}^{-2} \mathrm{yr}^{-1}\right) ; 2$ ) constant low 
nitrogen input $\left(10 \mathrm{mmol} \mathrm{m} \mathrm{m}^{-2} \mathrm{yr}^{-1}\right)$; and a ramp from the low to the high nitrogen input levels beginning at year 11 in the simulation and increasing linearly to year 90 . The nitrogen was added as equal amounts of $\mathrm{NO}_{3}$ and $\mathrm{NH}_{4}$ ions.

Results for input/output fluxes and nitrogen pools (land use change effects)

The simulated nitrogen response to forest growth under high deposition was a decrease in output flux as the nitrogen requirements for the biomass increases were met (Fig. 5A). Note that the system was at -steady state initially with input and output fluxes of $200 \mathrm{mmol} \mathrm{m} \mathrm{m}^{-2}$ $\mathrm{yr}^{-1}$, so the change in output flux of almost $-200 \mathrm{mmol}$ $\mathrm{m}^{-2} \mathrm{yr}^{-1}$ by year 30 of the simulation means that the output of inorganic nitrogen from the system was reduced almost to zero during peak forest growth. Build-up of nitrogen in the plant and LOM compartments was rapid (Fig. 5B). In spite of the retention of the nitrogen that had been leached before forest growth began, the biomass increases of the plant and LOM compartments required additional nitrogen from the ecosystem. This additional nitrogen was derived from the ROM compartment as evidenced by the negative changes in ROM nitrogen (Fig. 5B). In essennce the ecosystem 'mined' nitrogen from the soil compartment to suppert forest growth. This internal reallocation of nitrogen occurred even in the presence of a relatively high deposition of nitrogen. After canopy closure and stabilization of the carbon pools (year 40 in the simulation), ROM nitrogen began to recover to its original level. This re-storage of nitrogen in the bulk soil organic matter delayed the recovery of output flux so that by the end of the simulation outputs had not completely recovered to preafforestation levels. The output flux did begin to increase, however, as the new forest stabilized, and outputs continued to increase as the forest aged.

Under low constant nitrogen deposition (Figs. $5 C$ and 5D), the decline in output fluxes was less than that for high deposition. The steady state system before planting,

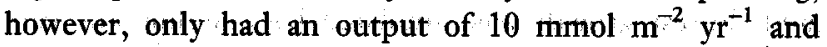
this was reduced to zero very early in the forest sequence and remained at zero throughout the simulation. Unlike the forest planted at high deposition (Fig. 5A), the forest planted at low deposition (Fig. 5C) did not show a pattern of increased leaching losses with age after canopy closure In this system there was much less nitrogen available from external sources for forest growth, so the 'mining' of nitrogen from the ROM compartment was much larger (Fig. 5D). The plant compartment in both the high and low deposition situations achieved the same nitrogen pool size at about the same time. The LOM compartment in the simulation under low deposition was, however, considerably nitrogen deficient compared to the high deposition situation.

The behaviour of the bulk soil nitrogen compartments in the low deposition scenario were also markedly different from those of the high deposition scenario (Figs. 5B and 5D). The nitrogen content of the ROM compartment under low deposition did not recover as the forest stabilized. There was also a net loss of adsorbed nitrogen under the low deposition scenario as opposed to the net gain in adsorbed nitrogen simulated for the high deposition case

Under a ramped deposition increase (Figs. 5E and $5 \mathrm{~F}$ ), an intermediate situation was simulated. The beginning of forest growth was similgr to the low deposition case but the final system responses resembled more the high deposition situation. The 'mining' of organic nitrogen eatised a decrease in ROM nitrogen to a lower level than under the high deposition scenario, but, unlike the low deposition scenario, the ROM nitrogen content did increase again after forest maturation. These changes reflected the enhanced availability of nitrogen as deposition increased through time and forest development slowed. Plant compartment nitrogen content again reached the same levels at the same time as in the other scenarios. The LOM nitrogen response was intermediate between those of the low and high situations. Adsorbed nitrogen showed an initial lass but increased above initial levels near the end of the simulation. Output fluxes (Fig. $5 \mathrm{E}$ ), as in the low deposition scenario went to zero (change in output equal to $-10 \mathrm{mmol} \mathrm{m} \mathrm{mr}^{-1}$ ) and remained at zero until very late in the simulation when leaching finally began (at about year 80).

These simulation results are in broad agreement with observed and hypothesized behaviour of nitrogen dynamics in growing forests although time series of data describing the dynamics of all ecosystem compartments at a site are not available. The onset of nitrogen leaching simulated by the model resulted from increased or prolonged nitrogen deposition and decreased plant requirement for nitrogen with age. These patterns are at least qualitatively consistent with observations and experimental data (Wright et al. 1995, Stoddard 1994). The quantitative correctness of the model is examined by Emmett $e t$ al. (in press) in a further paper.

\section{Results for internal nitrogen fluxes (land-use change effects)}

The increases in nitrogen uptake were much larger for the land-use change simulations (Figs. 6A and 6C) than for the deposition effects simulations (Figs, $4 \mathrm{~A}, 4 \mathrm{C}$ and $4 \mathrm{E})$. This was to be expected in that the simulated forest growth required a large sequestration of nitrogen. The large change in mitrogen release from the LOM compartment (Figs. 6B and 6C) was also expected because of the increased decomposition of the LOM compartment as the simulated forest matured. What was not necessarily to be expected was the decline in tuptake by the ROM compartment (Figs $6 \mathrm{~A}$ and $6 \mathrm{C}$ ). This decline oceurred because the pkant and LOM compartments had a higher demand for nitrogen during the simulated growth phase 

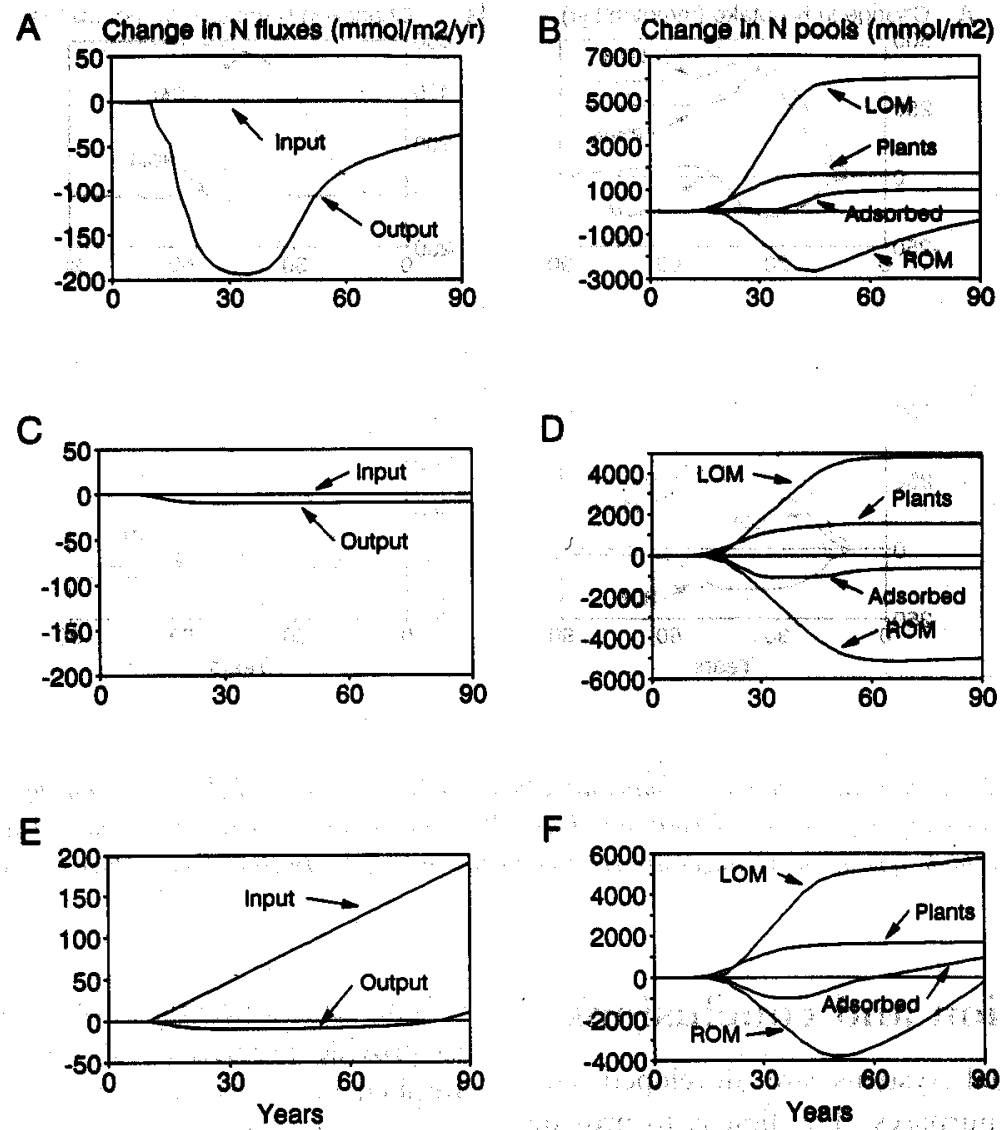

Fig. 5 Changes in the simulated responses of the nitrogen input/output fluxes ( $A, C$ and $E$ ) and the nitrogen contents of the organic compartments $(B, D$ and $F)$ in response to a land use change implemented under three scenarios of inorganic nitrogen deposition: $A$ and $B$ ) high constant deposition, $G$ and $D$ ) low constant deposition; $E$ and $F$ ) ramp increase from tow to high deposition. Changes are relative to the initial steady state conditions (first ten years of the simulations).

of the forest and 'out-competed' the ROM compartment for the available nitrogen (a demonstration of the dynamic competition for nitrogen inherent in the structure of the model).

There was not much difference in the changes of internal fluxes, however, between the two levels of deposition when only the land-use change scenarios are considered. Changes in uptake and release at high deposition (Figs. 6A and 6B) are slightly larger than for the low deposition case (Figs. 6C and 6D), largely due to the increased nitrogen availability under high deposition. The results for the ramp deposition scenario are not shown because they are intermediate between the two very similar situations already displayed.

\section{Discussion of land-use change effects}

For all three land-use change simulations; forest growth promoted net nitrogen mineralization in the ROM compartment and net nitrogen immobilization in the LOM compartment during forest growth. This re-allocation of internal nitrogen stores was necessary even under relatively high deposition conditions. In all cases, the plarit compartment took up nitrogen to the same degree. Note, however, that under the simplified conditions of these simulations there was no attempt to reduce plant carbon productivity in the low depositibut seenario. While this may be a questionable assumption, the magnitudes of the changes in the other compartinents were so large relative to the changes in the plant compartment, that it is not likely that changes in plant productivity of $20 \%$ or $30 \%$ as a result of fitrogeth fithitation would have changed the overall patterns sithulated here. Those patterns are: 1 ) that forest gtowth, even under high deposition, requires reallocation of internally stored nitrogen; 2) that leaching of nitrogen froth afforested sites will be reduced or even prevented during the active growing phase regardless of deposition level; and 3 ) that leaching from mature forests may be delayed or accelerated deperiding on the deposition history to the site and the degree to which the forest used internal nitrogen sources during the growth phase. 

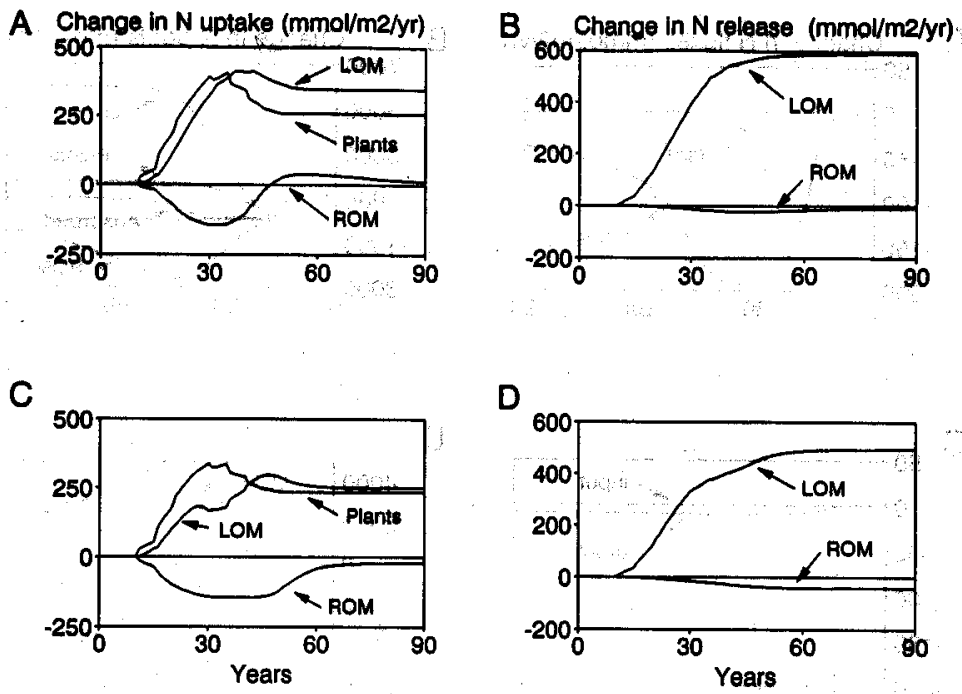

Fig. 6 Changes in simulated internal nitrogen fluxes (mineralization-A,C,E; uptake-B,D,F) in response to a land use change implemented under three scenarios of inorganic nitrogen deposition: $A$ and $B$ ) high constant deposition; $C$ and D) low constant deposition; $E$ and F) ramp increase from low to high deposition. Changes are relative to the initial steady state fluxes (first ten years of the simulations).

\section{General discussion and conclusions.}

Models of environmental systems are developed and applied for two general purposes. The first is to provide aid or direction in solving a problem or understanding a complex system. Models developed for these heuristic purposes (and the assumptions embodied within the models) may often be unjustified or even incapable of justification. These models are useful primarily as exploratory problem solving tools. The construction of these models and their subsequent use for speculative simulation is a self-education process. These models are tools to express and test hypotheses about the functioning of simple or complex systems. The putputs of such models do not need to be quantitative to be useful or to provide tests of the model, Often it is the case that reliable or extensive quantitative observations from the system being modelled are not available, so evaluation of these models must often be based on qualitative behaviours. The fact that such models cannot be verified quantitatively, however, does not diminish the utility of these models in advancing knowledge from a perceptual understanding of a problem (an intuitive or empirical cognition based on observation) to a conceptual expression of the problem (a complex, symbolic product of abstract or reflective reasoning). The models, once constructed, often guide the collection of data for further model testing and refinement of ideas by highlighting the inevitable consequences of the assumptions and the current understanding of system functioning that has been incorporated in the model structure.
The second general purpose for constructing models is to provide predictions of future behaviour of a system. Implicit in the use of models for this purpose is the need or desire to take some management action based on the outcame of the model predictions. The costs of such management actions are often large. As a result, models used for predictive purposes are subject to different standards of testing and acceptance than are models used for heuristic purposes. It is not enough that the models provide insight into the system processes. Predictive models must be shown to function correctly and consistently to establish confidence in the use of their predictions. Predictive models do not necessarily have to be quantitative to be useful. Models that simply predict whether or not some event occurs (a qualitative response) can be valuable in making policy decisions. Most often however, predictive models are used in quantitative analyses. In either ase; measures of the reliability of the models are noeded to edrablish confidence in their use. Model reliability is most often assessed through validation or verification exercises. The models are used to predict system responses in given situations and the model predictions are compared to observation of real system response. The paradigm for such tests requires that the data used in the test were not used in constructing or calibrating the model. As an increasing number of such tests are performed and the model functions reliably in each case, confidence in the madel's predictive capabilities grows.

It is often the case that the same model will be (or must be) used for both heuristic and predictive purposes, 
particularly in the analysis of environmental systems. This is the case for the model presented here. Construction of MERLIN was guided as much by a need to understand the influences of linked biotic and abiotic processes on nitrogen dynamics in ecosystems as by a need to provide a (preliminary) tool to predict future ecosystem response to atmospheric nitrogen deposition. This paper demonstrates the heuristic utility of the modelling procedure: the perception of the problem (nitrogen leaching), the conceptualization of the processes involved (the model structure) and the examination of the implications of current assumptions and understanding of nitrogen dynamics incorporated in the model structure (the speculative simulations). Based on the analyses presented here, MERLIN appears to be a usefut tool for examining the retention and loss of nitrogen at the plot or catchment scale in response to changes in nitrogen deposition and/or land-use changes. The structure of the model is process-based, the aggregation of components is consonant with those field measurements most frequently available, the dynamic responses of the model are consistent with many current observations on nitrogen dynamics in natural and manipulated systems, and the model can be used to focus and guide future field experiments and data collection efforts.

\section{Acknowledgements}

This work was supported in part by the Commission of European Communities (NITREX STEP-CV90-0056, NITREX ENVIRONMENT CT93-0264 and CT94-0436, DYNAMO ENV4-CT95-0030), the Research Council of Norway, the Natural Environment Research Council, the Institute of Hydrology, the Scottish Q Qffice Agriculture, Environment and Fisheries Department, the Norwegian Institute for Water Research, and the University of Amsterdam.

The research described in this article has also been funded in part by the U.S. Environmental Protection Agency agreement (CR820461-01-1) to the University of Virginia and in part by a grant from the U.S. Department of Energy to E\&S Environmental Chemistry, Inc. (DE-FG06-94ER30235),but it has not been subjected to review by either agency, does not necessarily reflect the views of either agency, and no official endorsement should be inferred. SC Contribution 3/95

\section{References}

Aber JD, Nadelhoffer KJ, Steudler P \& Melillo JM (1989) Nitrogen saturation in northern forest ecosystems. Bioscience 39: $378-386$

Aber JD, Melillo JM, Nadelhoffer KJ, Pastor J \& Boone RD (1991) Factors controlling nitrogen cycling and nitrogen saturation in northern temperate forest ecosystems. Ecological Applications 1: 303-315.

Aber JD \& Federer CA (1992) A generalized, lumped parameter model of photosynthesis, evapotranspiration and net primary productivity in temperate and boreal forest ecosystems. Oecologia 92: 463-474.
Ågren GI \& Bosatta E (1988) Nitrogen saturation of terrestrial ecosystems. Environ. Pollut. 54: 185-197.

Ågren G, McMurtie RE, Parton WJ, Pastor J \& Shugart HH (1991) State-of-the-art models of production-decomposition linkages in conifer and grassland ecosystems. Ecological Applications 1: 118-138.

Bergstrom L \& Jarvis N J (1991) Prediction of nitrate leaching losses from arable land under different fertilization interisities using the SOIL-SOILN models. Soil Use and Management 7: 79-85.

Bormann FH, Likens GE \& Melillo JM (1977) Nitrogen budget for an aggrading northern hardwood forest ecośystem. Science 196: 981-983.

Brandon O, \& Huttl RF (Eds) (1990) Nitrogen Saturation in Forest Ecosystems. Kluwer Academic Publishers, 135 pp.

Browen DJA (1988): Effect i of atrnospheric $\mathbb{N}$ deposition on surface water chemistry and the implications for fisheries. Enviran. Pollbut : 54 : $275+284$

Dise NB \& Wright RE (1995) Nitrogen leaching from European forests in relation to nitrogen deposition. Forest Ecol. Manag. 71: 153-163.

Eckersten H, Gardenas-Revrslag A \& Jansson PE (1995) Modelling daily nitrogen, carbon, water and heat flows of the Solling spruce stand. Ecological Modelling 83: 103-110.

Emmett BA, Reynolds B, Stevens PA, Norris DA, Hughes S, Gorres J \& Lubrecht I (1993) Nitrate leaching from afforested Welsh catchments-interactions between stand age and nitrogen deposition. Ambio 22: 386+394.

Emmett BA, Cosby BJ, Ferrier RC, Jenkins A, Tietema A $\& *$ Wright $\backslash$ RF (In press) Modelling the ecosystem effects of nitrogen deposition: Simulation of nitrogen saturation at a Sitka spruce forest, Aber, Wales, UK. Biogeochemistry.

Ferrier RC, Jenkins A, Cosby BJ, Helliwell RE, Wright RF \& Bulger AJ (1995) Effects of future $\mathrm{N}$ deposition scenarios on the Galloway region of SW Scotland using a coupled sulphur and nitrogen model (MAGIC-WAND). Water, Air: and Soil Pollut. 85: 707-712.

Galloway JN, Levy HII \& Kasibhatta PS (1994) Year 2020: consequences of population growth and development on deposition of oxidized nitrogen. Ambio 23: 120-123.

Groenenberg BJ, Kros H, van der Salm C \& de Vries W (1995) Applicaton of the model NUCSAM to the Solling spruce site. Ecological Modelling 83: 97-107.

Hamilton GJ \& Christie JM (197.1) Forest Management Tables (Metric). Forestry Commission Booklet No. 34, H.M.S.O., London.

Harriman R (1978) Nutrient leaching from fertilized forest watersheds in Scotland. 7. Appl. Ecal. 15: 933-942.

Heilman PE, Dao TH, Cheng HH, Webster SR \& Christensen L (1982) Comparison of fall and spring applications of ${ }^{15} \mathrm{~N}$-labelled urea to Douglas fir: II. Fertilister nitrogen recovery in trees and soil after 2 years. Soil Sci: Soc: Am. 7: 46: 1300-1304.

Henriksen, A, Lien L, Traan TS, Sevaldrud IS \& Brakke DF (1988) Lake acidification in Norway-present and predicted chemical status Ambio 17: 259-266.

Hulm SC \& Killham K (1990) Response over two growing seasons of a Sitka spruce stand to ${ }^{15} \mathrm{~N}$-urea fertilizer. Plant and Soil 124, 65-72.

Jenkins A, Ferrier RC \& Cosby BJ (in press) A dynamic model for assessing the impacts of coupled sulphur and nitrogen deposition scenarios on surface water acidification. 7. Hydrol, in press. 
Johnson DW (1992) Nitrogen retention in forest soils. f. Environ. Quality 21:1-12.

Kahl JS, Norton SA, Fernandez IJ, Nadelhoffer KJ, Driscoll CT \& Aber JD (1993) Experimental inducement of nitrogen saturation at the watershed scale. Environ. Sci. Technol. 27: 565-568.

Krauchi N (1995) Application of the model FORSUM to the Solling spruce site. Ecological Modelling 83: 69-76.

Landsberg JJ, Kaufmann MR, Binkley D, Isebrandas J \& Jarvis PJ (1991) Evaluating progress towards closed forst models based on fluxes of carbon, water and nutrients. Tree Physiology 9: 1-15.

Likens GE, Bormann FH, Pierce RS, Eaton JS \& Johnson NM (1977) Biogeochemistry of a Forested Ecosystem. Springer-Verlag, New York.

Li, S, Munson R, Johnson D, Gherini S, Summons K, Hudson R, Wilkinson K \& Pietelka L (1991) Application of a nutrient cycling model (NuCM) to a northern mixed hardwood and a southern coniferous forest. Tree Physiology 9: 173-184.

Miller HG \& Miller JD (1987) Nutritional requirements of Sitka spruce. Proc. Roy. Soc. Edinburgh 93B: 75-83.

Miller HG, Miller JD \& Cooper JM (1980a) Biomass and nutrient accumulation at different growth rates in thinned plantations of Corsican pine. Forestry 53: 23-39.

Miller HG, Miller JD \& Cooper JM (1980b) Tables of biamass and accumulated nutrients at different growth ratesin, thinned plantations of Corsican pine. Macaulay Land Use Research Institute Publication, Aberdeen, Scotland.

Moldan F, Hultberg H, Nyström U \& Wright RF (1995) Nitrogen saturation at Gårdsjön, southwest Sweden, induced by experimental addition of ammonium nitrate. Forest Ecol. Manag. 71: 89-97.

Nambiar EKS \& Bowen GD (1986) Uptake, distribution and retransolocation of nitrogen by Pinus radiata from ${ }^{15} \mathrm{~N}-$ labelled fertilizer applied to podsolized sandy soil. Forest Ecol. Manag. 15: 269-284.

National Academy of Sciences (1969) Eutrophication: Causes, Consequences, Correctives. Washington D.C. National Academy Press.

National Research Council (1991) Environmental Epidemiology: Public Health and Hazardous Wastes. Washington D.C. National Academy Press.

Nilsson J, (Ed.) (1986) Nitrogen Saturation: Abstracts from a morkshop. Statens Naturvardsverk Rapport 3153 (1986), Box 1302, 17125 Solna, Sweden.

Preston CM \& Mead DJ (1994) Growth response and recovery of ${ }^{15} \mathrm{~N}$-fertilizer one and eight growing seasons after application to lodgepole pine in British Columbia. Forest Ecol. Manag. 65: 219-229.

Rastetter EB, Ryan MG, Shaver GR, Melillo JM, Nadelhoffer KJ, Hobbie JE \& Aber JD (1991) A general biogeochemical model describing the responses of the $\mathrm{C}$ and $\mathrm{N}$ cycles in terrestrial ecosystems to changes in $\mathrm{CO}_{2}$, climate, and $\mathrm{N}$ deposition. Tree Physiology 9: 101-126.

Running SW \& Gower ST (1991) Forest-BGC - A Gongral model of forest ecosystem processes for regional applications. II. Dynamic carbon allocation and nitrogen budgets. Tree Physiology 9: 147-160.

Schall P (1991) Productivity and vitality of spruce stands: dynamic feedback simulation for responses to different annual and seasonal levels of magnesium supply from soil. Vegetation 92: 111-118.

Shugart HH (1984) A Theary of Forest Dynamics. Springer-Verlag, New York.

Stevens PA, Norris DA, Emmett BA, Gorres J, Reynolds B, Hughes S, Williams TG, Sparks TH \& Lubrecht WC (1992) Annual report for 1992 of the Nitrogen deposition manipulation study. I Forest nitrogen survey. National Power/Powergen Joint Environment Programme/NERC Contract LC/5/ 0004 DoE/NERC Contraćt PECD 7/12/110.

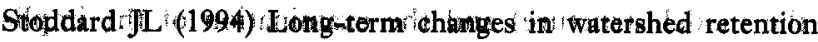
of nituagent its causes and aquatic consequences. In: Baker L (Ed) Enviranmental Chemistry of Lakes and Reservoirs. (pp. 223-284). Adyances in Chemistry Series, No. 237, American Chemical Society, Washington, DC.

Thornley JHM \& Cannell MGR (1992) Nitrogen relations in a forest plantation-soil organic matter ecosysttem model. Annals of Botany 70: 137-151.

Tietema A, Wright RF, Blanck $K$, Bredemeier M, Emmett BA, Gundersen P, Hultberg H, Kjønaas OJ, Moldan F, Roelofs JGM, Schleppi P, Stuanes AO \& van Breemen N (1996) NITREX: the timing of response of coniferous ecosystems to experimentally-changed nitrogen deposition. Water Air Soil Pallut. 85: 1623-1628.

van Breemen N \& van Dijk HFG (1988) Ecosystem effects of atmospheric deposition of nitrogen in the Netherlands. Environ. Pollut. 54:249-274.

van Dam D \& van Breemen N (1995) NICCCE: A model for turnover of nitrogen and carbon isatopes in coniferpis ecosystems. Ecological Modeling 79: 255-275.

van Miegroet $H$ \& Johnson DW (1993) Nitrate dynamics in forest soils. In: Burt TP, Heathwaite AL \& Trudgill ST (Eds) Nitrate: Processes, Patterns and Management (pp. 75-97). John Wiley \& Sons, New York.

van Miegroet $\mathrm{H}$; Cole DW \& Foster NW (1992) Nitrogen distribution and cycling. In: Johnson DW \& Lindberg SE (Eds) Atmospheric Deposition and Forest Nutrient Cycling (pp. 178-196). Springer-Verlag, New York.

van Oene $\mathrm{H}$ (1992) Acid deposition and forest nutrient imbalances. A modelling approach. Water Air Soil Pollut. 6: 33-50.

Vitousek PM, Gosz JR, Grier CC, Melillo JM, Reiners WA \& Todd RU (1979) Nitrate losses from disturbed ecosystems. Science 204: $469-474$.

Vitousek P M \& Howarth R W (1991) Nitrogen limitation on land and in the sea: how can it occur? Biogeochemistry 13: 87-115.

Weinstein DA, Beloin RM \& Yanai RD (1991) Modelling changes in red spruce carbon balance in response to intervening ozone and nutrient stresses. Tree Physiology 9: 127-146.

Wright RF, \& van Breemen N (1995) The NITREX project: an introduction. Forest Ecol. Manag. 71: 1-6.

Wright RF, Roelofs JGM, Bredemeier M, Blanck K, Boxman AW, Emmett BA, Gundersen P, Hultberg H, Kjønaas OJ, Moldan F, Tietema A, van Breemen N \& van Dijk HFG (1995) NITREX: response of coniferous forest ecosystems to experimentally-changed deposition of nitrogen. Forest Ecol. Manag. 71: 163-169. 